\title{
EL FUTURO PRÓXIMO DEL ARBITRAJE DE INVERSIONES EN COLOMBIA*
}

\author{
THE NEAR FUTURE OF INVESTMENT \\ ARBITRATION IN COLOMBIA \\ O FUTURO PRÓXIMO DA ARBITRAGEM \\ DE INVESTIMENTO NA COLOMBIA. \\ L'AVENIR DE L'ARBITRAGE
D'INVESTISSEMENTS EN COLOMBIE
}

Raúl Alberto Gallardo Ciro ${ }^{a}$ raulgallardoc@yahoo.com

Fecha de recepción: 23 de Julio 2014 Fecha de revisión:11 de Septiembre 2014 Fecha de aceptación: 6 de Octubre 2014

\section{RESUMEN}

Colombia no tiene una gran experiencia en el arbitraje internacional de inversiones por los conflictos surgidos entre inversionistas extranjeros y el Estado. A pesar de que el Convenio sobre Arreglo de Diferencias Relativas a Inversiones entre Estados y Nacionales de Otros Estados, o Convención de Washington, fue ratificada en el año de 1997, no se conoce la primera demanda contra el Estado ante el Centro Internacional de Arreglo de Diferencias Relativas a Inversiones (CIADI), creado por la Convención de Washington para dirimir los conflictos surgidos de una inversión. La nueva política de celebración de tratados bilaterales de inversión y de los tratados de libre comercio en nuestro país, traerá, con total seguridad, los primeros litigios ante el CIADI y otras instancias arbitrales internacionales por los conflictos entre inversionistas extranjeros y las entidades estatales. El arbitraje de inversiones

* Artículo de investigación científica y tecnológica.

a. Abogado egresado de la Universidad del Rosario. Especialización en Derecho Civil, Universidad de Paris II Panthéon-Assas, Francia. Master II en Derecho Privado General, Universidad de Paris II Panthéon-Assas, Francia. Master II en Arbitraje y Comercio Internacional, Universidad de Versalles St Quentin en Yvelines, Francia. Admitido al examen del Colegio de Abogados de París. Abogado litigante y consultor.

MISIÓN JURÍDICA Revista de Derecho y Ciencias Sociales Bogotá, D.C. (Colombia) Colaboradores Externos Internacionales Núm. 7, Año 2014 enero-diciembre, pp. 167-197. ISSN 1794-600X 
tiene ventajas evidentes para los inversionistas que vengan al territorio, sin embargo, también representa un peligro para el Estado colombiano si no se adoptan medidas responsables para esperar la llegada de este nuevo método de resolución de conflictos. La tendencia latinoamericana actual es la de rechazar el CIADI como Centro de organización del arbitraje internacional de inversiones, mientras que en Colombia, comenzamos a abrirle por primera vez en la historia las puertas a esta figura.

\section{PALABRAS CLAVE}

Arbitraje internacional, Inversiones, CIADI, Convención de Washington, Tratados Bilaterales de Inversión.

\section{SOMMAIRE}

La Colombie ne dispose pas d'une expérience marquante en matière d'arbitrage international d'investissement. Cela s'explique principalement par l'absence de traités d'investissement jusqu'à une époque récente. La Colombie a signé et ratifié la Convention pour le Règlement des Différends Relatifs aux Investissements entre Etats et Ressortissants d'autres Etats, communément dénommée la Convention de Washington, depuis 1997. Pourtant, aucune demande n'a été encore introduite au jour d'aujourd'hui contre l'Etat colombien devant le Centre de résolution des litiges spécifiquement créé par la Convention de Washington, autrement dit le Centre International pour le Règlement des Différends Relatifs aux Investissements (CIRDI). La nouvelle politique du gouvernement dans la négociation des traités bilatéraux d'investissements et des traités de libre-échange dans notre pays entraînera avec certitude l'introduction des premières demandes devant le CIRDI, ainsi que devant d'autres instances internationales pour les conflits futurs qui impliqueront les investisseurs étrangers et les entités étatiques. L'arbitrage d'investissement présente des avantages considérables pour les investisseurs qui souhaitent venir investir sur le territoire colombien, mais il représente également un risque pour l'Etat colombien si celui-ci ne prend pas les mesures politiques, économiques et juridiques adéquates dans le but d'accueillir dans son système ce mode alternatif de résolution des conflits. La nouvelle tendance en l'Amérique Latine consiste à rejeter la compétence du CIRDI comme Centre d'organisation des arbitrages internationaux d'investissements alors que la Colombie tente d'ouvrir ses portes à cette alternative pour la première fois dans l'histoire.

\section{MOTS-CLÉS}

Arbitrage international, Investissement, CIRDI, Convention de Washington, Traités Bilatéraux d'Investissement.

\section{ABSTRACT}

Colombia does not have very much experience in International Investment Arbitration for disputes arising between foreign investors and States. Despite the entry into force of the Convention on the Settlement of Investment Disputes between States and Nationals of Other States or Washington Convention since 1997, there is no precedent of a request for arbitration before the International Centre for Settlement of Investment Disputes (ICSID), created by the Washington Convention, to resolve disputes arising from investments. In the last years the Colombian government has celebrated and ratified several Bilateral Investment Treaties (BIT) and free trade agreements (FTA) that will bring with absolute certainty before the ICSID and others arbitral institutions the first cases for disputes between foreign investors and state entities. Investment arbitration has significant advantages for foreign investors interested in coming to Colombian territory, however it also represents a risk to the State if responsible measures are not taken in order to anticipate the new coming of the this alternative dispute resolution method. Currently the trend in Latin America is to reject ICSID as the organizational Center for Investment Arbitration while Colombia is opening the doors to Investment Arbitration for the first time in history.

\section{KEY WORDS}

International arbitration, Investment, ICSID, Washington Convention, Bilateral Investment Treaties.

\section{RESUMO}

A Colômbia não tem uma grande experiência na arbitragem de investimento internacional para disputas entre investidores estrangeiros e do Estado. Embora a Convenção para a Resolução 
de Diferendos Relativos a Investimentos entre Estados e Nacionais de Outros Estados, ou Convenção de Washington, foi ratificada em 1997, o primeiro processo contra o Estado não é conhecido perante o Centro Internacional para a Resolução de Disputas relativas ao Investimento (ICSID), estabelecido pela Convenção de Washington para resolução de litígios decorrentes de um investimento. A nova política de tratados bilaterais de investimentos e de livre comércio em nosso país, trará toda a segurança, os primeiros casos perante o ICSID e outros processos de arbitragem internacional para disputas entre investidores estrangeiros e entidades estaduais. Arbitragem de investimento tem vantagens claras para os investidores que vêm para o território, no entanto, também representa um perigo para o Estado colombiano se medidas responsáveis não forem tomadas para aguardar a chegada deste novo método de resolução de conflitos. A tendência atual da América Latina está a rejeitar o ICSID como centro da organização de arbitragem internacional de investimento, enquanto na Colômbia, começamos a abrir pela primeira vez na história as portas a esta figura.

\section{PALAVRAS-CHAVE}

Arbitragem internacional, investimentos, ICSID, Convenção de Washington, Tratados de investimento bilaterais.

\section{METODOLOGÍA}

La investigación de corte teórico, se realizó a través de fuentes directas de artículos que se encuentran en bases de datos internacionales, libros sobre la materia, artículos de prensa y documentos disponibles en internet.

\section{RESULTADOS}

Se requiere de una verdadera conciencia institucional del Estado colombiano para que sus Entidades conozcan las ventajas y desventajas del sistema al momento de adelantar contrataciones. De la misma manera el inversionista colombiano debe conocer las posibilidades que ofrece el sistema entre los países que han celebrado tratados de inversión. La aplicación de un sistema desconocido para la mayoría del ámbito jurídico colombiano traerá sin lugar a dudas choques inevitables con las instituciones jurídicas internas.

\section{INTRODUCCIÓN}

El arbitraje de inversiones se acerca, cada vez más rápido, al territorio colombiano. Esto no significa que sea totalmente desconocido para el país, o que se aproxime para destruir todo a su paso. Lo que resulta cierto es que al parecer no se le da la importancia que merece. Este tipo de arbitraje va a llegar y sus consecuencias podrían superar cualquier expectativa. Pero entonces, ¿por qué el desconocimiento de tal arbitraje en nuestra práctica jurídica colombiana? La razón es sencilla: La ausencia hasta hace pocos años de tratados de libre comercio o de tratados bilaterales de inversión concluidos por Colombia.

La globalización y la búsqueda de mercados extranjeros por parte de los inversionistas han propiciado la negociación de tratados entre Estados, con el fin de proteger a los inversionistas de potenciales vulneraciones en el país receptor de la inversión. De esta manera se llegó a la celebración de tratados bilaterales de inversión (TBI) y de tratados de libre comercio (TLC), que en muchos casos incluyen capítulos destinados a la inversión. Con el paso del tiempo, los conflictos entre inversionistas extranjeros y entidades estatales comenzaron a ser resueltos por tribunales de arbitraje internacional de inversiones, y esto impulsado, en gran medida, por el Convenio sobre Arreglo de Diferencias Relativas a Inversiones entre Estados y Nacionales de Otros Estados, o Convención de Washington, de 1965 que entró en vigor en Colombia el 14 de agosto de 1997, y que propició la creación del CIADI o Centro Internacional de Arreglo de Diferencias Relativas a Inversiones ${ }^{1}$.

¿Por qué no se conoce de diferendos entre inversionistas extranjeros y el Estado Colombiano resueltos por tribunales de inversiones bajo las reglas del CIADI? La respuesta se encuentra en el consentimiento que las partes deben proporcionar en caso de conflicto para darle competencia a este tribunal. El hecho de ratificar la Convención de Washington no implica, por sí mismo, un consentimiento expreso de Colombia para acudir

1 Convenio del Centro Internacional de Arreglo de Diferencias Relativas a Inversiones (CIADI) de 1965. Al 18 de junio de 2013, la Convención de Washington cuenta con 158 Estados signatarios, de los cuales, 148 han ratificado, aceptado o aprobado la Convención. https://icsid.worldbank.org/ICSID/FrontServlet?re questType $=$ CasesRH\&actionVal=Show Home\&pageName $=$ Memb erStates_Home 
al arbitraje de inversiones. El consentimiento del Estado debe encontrarse, a su vez, en una ley, en un acuerdo entre las partes, o en un tratado, para que se pueda entender que ha aceptado la jurisdicción del tribunal internacional. La nueva tendencia del gobierno colombiano sobre suscripción de tratados con distintos países va a tener como consecuencia necesaria los primeros arbitrajes internacionales de inversión para este país suramericano con base en la violación de un tratado.

¿Es esto conveniente? El arbitraje de inversiones tiene sus ventajas $\mathrm{y}$ no debe, necesariamente, descartarse como un método de resolución de conflictos, pero existen evidentes riesgos que el Estado Colombiano debe sopesar. Además, se requiere de una buena organización interna, para que los entes estatales sean conscientes de las obligaciones internacionales contraídas por Colombia.

El arbitraje de inversiones ha sido anunciado como un arbitraje encargado de defender los derechos de los inversionistas extranjeros, aunque es al mismo tiempo un arbitraje que protege los derechos de los Estados receptores de la inversión, depositario de la confianza de las partes. A pesar de esto, los cuestionamientos al sistema no se han hecho esperar.

Llega un nuevo arbitraje a Colombia para los conflictos entre Estados e inversionistas extranjeros que requiere un examen de su origen y virtudes (1). No obstante, los operadores jurídicos deben ser conscientes de las consecuencias de lo que se avecina. El arbitraje de inversiones necesita replantearse, con el único objetivo de que reviva con más fuerza, que sea más justo, más real. Como toda creación humana, tiene sus flaquezas, debilidades que deben denunciarse para corregirse, o tan solo para estar lo mejor preparados que se pueda (2).

\section{El desarrollo de un nuevo arbitraje en Colombia para los conflictos entre Estados e inversionistas extranjeros}

En Colombia estamos acostumbrados al arbitraje nacional, ya sea comercial o estatal. El primero se refiere al arbitraje pactado en caso de conflicto entre particulares y el segundo, al arbitraje en el que se inmiscuye una persona de derecho público. También se conoce el arbitraje comercial internacional, que en Colombia no ha sido muy frecuente dada la incertidumbre que reina en nuestra tradición jurídica alrededor de la figura, y el temor de entregar la resolución de conflictos a un tribunal de arbitraje internacional. Pese a ello, podría pensarse que la Ley 1563 de 2012, por medio de la cual se expidió el nuevo Estatuto de Arbitraje Nacional e Internacional en Colombia, incentivará un mayor número de arbitrajes comerciales internacionales, pero eso está por verse. Por último, tenemos el arbitraje internacional de inversiones, el cual no ha tenido un gran desarrollo en Colombia y del cual nos ocuparemos en este escrito.

Para entender las implicaciones del arbitraje de inversiones es necesario: (1) repasar su origen; (2) Acto seguido, entender por qué se ha hablado de un nuevo salvador y las ventajas que representa en nuestro días concluir tratados bilaterales de inversión o tratados de libre comercio que incluyen capítulos de inversión y en donde se contempla el arbitraje internacional de inversiones.

\subsection{El origen del arbitraje de inversiones en los conflictos entre inversionistas extranjeros y Estados receptores de la inversión}

Los conflictos entre Estados e inversionistas extranjeros son tan antiguos como las operaciones comerciales sobre las cuales se fundamentan, asimismo los métodos de resolución de conflictos en caso de diferendo. A pesar de esto el arbitraje internacional de inversiones no ha sido siempre el método preferido para llegar a un acuerdo que ponga fin a la disputa. En la evolución misma de la resolución de controversias internacionales se encuentra el origen de los tratados de inversión y del arbitraje de inversión.

\subsubsection{El nacimiento de una nueva clase de arbitraje: El arbitraje de inversiones}

El arbitraje internacional de inversiones constituye una clase distinta del arbitraje que conocemos, creado, hace muchas décadas, producto de la guerra de fuerzas entres los países desarrollados y las economías en vía de desarrollo². En efecto,

2 El banco mundial realiza una clasificación de las economías basada en el ingreso nacional bruto per cápita. Según esto, cada economía se clasifica como de ingreso bajo, ingreso mediano (que se subdivide en mediano bajo y mediano alto) o ingreso alto. El banco mundial realiza una tabla que es actualizada cada año. En el siguiente link se puede encontrar la última clasificación de países disponible en la página oficial del banco mundial: http:// 
existen muchas historias que dan cuenta de discusiones diplomáticas que llegaban, muchas veces, hasta los enfrentamientos armados entre naciones. Hasta hace más de un siglo, en caso de conflicto, el inversionista buscaba la intervención de su gobierno, dando como resultado el envío por éste de unos emisarios muy "simpáticos y amistosos" que colocaban sus navíos de guerra en las fronteras del Estado receptor de la inversión hasta que la obligación contractual fuera ejecutada ${ }^{3}$.

Con el tiempo se fue superando este juego de "batalla naval" y el tratamiento a favor del inversionista extranjero fue cada vez mayor, ganando terreno ante los propios intereses de los nacionales de los países receptores de la inversión. La posición desventajosa de los países en vía de desarrollo, trajo como consecuencia que los doctrinantes propusieran soluciones para el reequilibrio de fuerzas. De esta manera se llegó a la doctrina Calvo en Latinoamérica, creada por el jurista Carlos Calvo, según la cual, un extranjero no podía esperar tener un mejor tratamiento, ni uno diferente, al de los propios nacionales. Los extranjeros debían someterse a la jurisdicción local, evitando las presiones que resultaban de los juegos diplomáticos y el poder desbordado de algunos países ${ }^{4}$. Ya no era el temor del uso de las armas lo que determinaría la contienda. La diplomacia por la fuerza empezó a desaparecer con la Convención para la Resolución Pacifica de Disputas Internacionales, celebrada en la Haya en 1907, dando paso a una nueva era, en la cual la protección diplomática y el arbitraje serían el nuevo método de resolución de conflictos ${ }^{5}$.

La Doctrina Calvo no fue de total agrado de las potencias económicas mundiales, y de sus inversionistas, y la arremetida no se hizo esperar. Poco a poco se construyó un sistema de tratados que permitiría un acceso directo a los métodos de solución de conflictos en tribunales internacionales, alejándose así de las

data.worldbank.org/about/country-classifications/countryand-lending-groups

3 BURGOS-DE LA OSSA, María Angélica \& LOZADA-PIMIENTO, Nicolás. (2009). La protección diplomática en el marco de las controversias internacionales de inversión. EN: Revista Colombiana de Derecho Internacional,15, p. 246. Ver igualmente: BLACKABY, Nigel. (2005). El Contrato de Arbitraje. EN: Legis (Ed.), El arbitraje según los tratados de inversión y los capítulos de inversión en los tratados de libre comercio. Colombia. p. 285.

4 BLACKABY, Nigel. Op. cit., p. 286.

5 Ibid., p. 287. jurisdicciones nacionales, consideradas poco atractivas, atendiendo la duración de los procesos, la influencia del propio Estado receptor de la inversión sobre sus jueces, y la supuesta tendencia del juez a proteger los intereses de su país de origen.

La creación de la Convención sobre el Reconocimiento y la Ejecución de las Sentencias Arbitrales Extranjeras, también conocida como Convención de New York de 1958 ${ }^{6}$, el Convenio sobre Arreglo de Diferencias Relativas a Inversiones entre Estados y Nacionales de Otros Estados, o Convenio de Washington, de $1965^{7}$ y la Convención Interamericana sobre Arbitraje Comercial Internacional, o Convención de Panamá, de $1975^{8}$ servirían de base para la adopción del arbitraje internacional como nuevo método de resolución de conflictos comerciales y de inversiones en el ámbito internacional. En el caso del arbitraje internacional de inversiones, es la Convención de Washington la que tiene mayor importancia. Dejemos claro algo, el Centro Internacional de Arreglo de Diferencias Relativas a Inversiones (CIADI) creado como consecuencia de la Convención de Washington y encargado de administrar los arbitrajes bajo la Convención, no es el único escenario para el arbitraje de inversiones. La CCI, la Corte Internacional de Arbitraje de Londres, la Corte Permanente de Arbitraje en la Haya, los arbitrajes bajo las reglas de la Comisión de las Naciones Unidas para el Derecho Mercantil Internacional (CNUDMI), entre otros, también conocen de este tipo de contencioso. Sin embargo el CIADI concentra una gran parte del litigio, debido a la regulación completamente autónoma de la Convención de Washington, desprovista de cualquier interferencia de los derechos o corte locales y las facilidades de ejecución del laudo arbitral bajo la Convención de Washington ${ }^{9}$.

La Convención de Washington de 1965 fue redactada a instancias del Banco Mundial para promover la inversión extranjera en los países

6 La Convención de New York entró en vigor en Colombia el 24 de diciembre de 1979.

7 El Convenio o Convención de Washington entró en vigor en Colombia el 14 de agosto de 1997.

8 La Convención de Panamá fue ratificada por Colombia el 29 de diciembre de 1986.

9BERNARDINI, Piero. (2009). Liber Amicorum Bernardo Cremades. ICSID Versus NON-ICSID Investment Treaty Arbitration. EN: M.A. Fernández-Ballesteros y D. Arias, La Ley (Ed.). 
en desarrollo, siendo completamente autónoma respecto de los sistemas legales nacionales. El logro más importante consistió en crear una instancia en la que los inversionistas pudieran demandar directamente a los Estados extranjeros. El Convenio impide a los Estados ejercer la protección diplomática cuando el litigio ya ha sido sometido al Centro. Solo autoriza su intervención en la fase de ejecución si el Estado perdedor no quiere cumplir el fallo arbitral. La Convención se aplica a los litigios surgidos directamente de la inversión, entre un Estado Contratante y un nacional de otro Estado Contratante, e igualmente que las partes hayan consentido por escrito someterlo al CIADI. Este consentimiento es el eje central de la interferencia del CIADI, la sola firma del Convenio no es suficiente, el consentimiento debe constar por escrito y de manera separada. Sin embargo, el consentimiento puede estar contenido en un Acuerdo Bilateral de Inversión, caso en el cual el acuerdo se entiende perfeccionado cuando el nacional de una de las partes impetra su solicitud de arbitraje.

Con relación al reconocimiento y ejecución de laudos arbitrales, los artículos 53, 54 y 55 de la Convención de Washington son lex specialis respecto de la Convención de Nueva York por tanto la Convención de Washington se aplica sin consideración a la Convención de Nueva York ${ }^{10}$.

Los casos de arbitraje ante el CIADI se han incrementado exponencialmente y Colombia seguramente hará parte de estas estadísticas. Entre 1972 y 1996 se registraron un total de 38 casos ante el CIADI. A partir de 1997 comenzó a explotar el número de casos a tal punto que entre 1997 y diciembre de 2012 se registraron 381 ante este Centro $^{11}$

\subsubsection{Un nuevo arbitraje en territorio colombiano}

Antes de la llegada de los tratados de inversión, los inversionistas solo podían protegerse a través

10 JANA LINETSKY, Andrés \& KLEIN KRANENBERG, Johanna. (2008). La convención de Nueva York y el CIADI Reconocimiento y Ejecución de Laudos Arbitrales bajo la Convención de Washington. EN: Abeledo Perrot (Ed.). El Arbitraje Comercial Internacional, Estudio de la Convención de Nueva York con motivo de su $50^{\circ}$ aniversario. Tawil, Guido Santiago \& Zuleta, Eduardo. Buenos Aires, p. 675

11 Centro Internacional de Arreglo de Diferencias Relativas a Inversiones -CIADI-. Carga de Casos del CIADI-Estadísticas. Edición 2013-1. del derecho internacional consuetudinario del estándar mínimo de tratamiento y la regla conocida como "Hull rule" para los casos de expropiación y la reparación pronta, adecuada y efectiva ${ }^{12}$. El primer tratado bilateral de inversión fue firmado entre Alemania con Pakistán en $1959^{13}$. A partir de este momento comenzó un nuevo movimiento de inclusión, en estos tratados, de métodos alternativos de resolución de conflictos para llevar el contencioso entre inversionistas de un Estado y el otro Estado parte, ante tribunales internacionales. En el caso latinoamericano, hasta 1989, tan solo Panamá y Belice habían aprobado el arbitraje como método de resolución de conflictos obligatorio en los litigios entre inversionistas extranjeros y Estados con base en un tratado. En 2005 la suma ascendió a 10 países (Uruguay, Bolivia, Argentina, Paraguay, Perú, Venezuela, Chile, México, Ecuador, y Nicaragua) ${ }^{14}$. Para 2013 ya existían registros de tratados de inversión en Guyana, Surinam, Costa Rica, El Salvador, Guatemala, Honduras, Panamá y Colombia en donde se contempla el arbitraje ${ }^{15}$.

Hoy en día existen en el mundo más de 3000 tratados, ya sea de inversión o de libre comercio, que incluyen capítulos de inversión, o acuerdos multilaterales $^{16}$ y en donde se ve, en su gran mayoría, cláusulas de resolución de conflictos a favor de tribunales internacionales de inversión.

Los tratados de inversión son la plataforma ideal para el arbitraje internacional de inversiones. Esta es la razón por la cual Colombia presenciará los primeros arbitrajes de inversión ante el CIADI, y otras instituciones, al entenderse incluido su consentimiento en los tratados suscritos. El consentimiento del Estado debe existir

12 NEUMAYER, Eric \& SPESS, Laura. (2005). Do Bilateral Investment Treaties Increase Foreign Direct Investment to Developing Countries?. EN: London School of Economics and Political Science, UK., p. 1570.

13 Ibid., p. 1569.

14 VAN HARTEN, Gus. (2010). Five Justifications for Investment Treaties: A Critical Discussion. EN: Trade, Law and Development. Vol. 2, No 1, p. 25.

15 United Nations Conference on Trade and Development. http://unctad.org/en/Pages/AboutUs.aspx

16 EBERHARDT, Pia \& OLIVET, Cecilia. (2012). Capitulo II, Controversias relacionadas con tratados de inversión, Un gran negocio para la industria del arbitraje. EN: Helen Burley (Ed.).

Cuando la injusticia es negocio. Cómo las firmas de abogados, árbitros y financiadores alimentan el auge del arbitraje de inversiones. Bruselas-Ámsterdam, p.14. 
posteriormente en una ley, en un contrato o en un tratado de libre comercio o de inversión ${ }^{17}$.

El artículo 25 (1) de la Convención de Washington dispone que:

La jurisdicción del Centro se extenderá a las diferencias de naturaleza jurídica que surjan directamente de una inversión entre un Estado Contratante (o cualquiera subdivisión política u organismo público de un Estado Contratante acreditados ante el Centro por dicho Estado) y el nacional de otro Estado Contratante y que las partes hayan consentido por escrito en someter al Centro. El consentimiento dado por las partes no podrá ser unilateralmente retirado.

En Colombia, el inversionista extranjero no poseía herramientas para buscar la constitución de un tribunal de arbitraje bajo el CIADI, a no ser que fuera directamente pactado en un contrato. Los recientes acuerdos comerciales y de inversión adelantados por el gobierno colombiano, tendrán como consecuencia la aparición de arbitrajes internacionales de inversión entre las entidades estatales y los inversionistas extranjeros ${ }^{18}$. Se repasarán cuáles instituciones de arbitraje han sido pactadas en los principales instrumentos que se encuentran suscritos, o que han entrando en vigor, hasta el día de hoy en nuestro país ${ }^{19}$. Esto permite que el lector se percate de que en realidad el CIADI se encuentra incluido, en gran parte, de

17VILLEGAS CARRASQUILLA, Lorenzo. (2011). Debates en torno al consentimiento al acuerdo arbitral por el Estado en el arbitraje internacional de inversiones. EN: Grupo Editorial Ibáñez (Ed.). Tratado de Derecho Arbitral. Bogotá, 2011, p. 442 a 445.

18 US. Embassy - Bogotá Colombia. (2011). An Overview of Arbitration in Colombia for U.S. Companies. Council of American Enterprises Colombian American Chamber of Commerce, p.9. Disponible en: http://export.gov/colombia/static/Report\%20 -\%20Arbitration\%20in\%20Colombia\%20-\%20final\%206-111_Latest_eg_co_033097.pdf

19 La validez de los tratados depende del derecho interno de cada Estado. En Colombia, el poder ejecutivo, a través del Presidente de la República, junto con el Ministerio de Relaciones Exteriores, procede a la negociación del instrumento y concluye con la adopción de un texto (art. 189, $n^{\circ} 2$. C.P.). La Rama Legislativa aprueba o desaprueba el tratado sometiéndolo a consideración mediante ley, sancionada luego por el Presidente de la República (Arts. 154. $150 n^{\circ}$ 16. 19, literales b, c, C.P.). Además de esto, la Corte Constitucional tiene que pronunciarse sobre la exequibilidad del tratado y de la ley aprobatoria (Control previo de constitucionalidad Art.241, $n^{\circ}$ 10. C.P.) Una vez declarado exequible, el Presidente de la República procede a la ratificación del tratado. ORJUELA, Carlos García. Senador de la República de Colombia. Ponencia presentada al Congreso durante los debates sobre el tratado de libre comercio. (2005). Competencias del Congreso de la República en Materia de Tratados Internacionales Procedimiento y Características de la Aprobación de Tratados Internacionales en el Ordenamiento Jurídico Colombiano. los tratados suscritos por Colombia como uno de los métodos de resolución de conflictos, y que no es la excepción a la regla. Basta con señalar que la gran mayoría de tratados prevén el agotamiento de ciertos recursos antes de acudir al arbitraje, ya sea negociaciones previas con las autoridades o periodos de cooling off, notificaciones sobre la existencia del conflicto por un periodo de tiempo determinado antes de acudir al arbitraje, o en ciertos casos el agotamiento de los recursos jurisdiccionales internos del Estado receptor de la inversión, antes de activar un arbitraje de inversiones. Por cuestiones metodológicas nos limitaremos a enunciar los principales métodos de resolución de conflictos en cada uno de los tratados de inversión, o que contiene un capítulo de inversión, sin considerar los requisitos previos propios a cada uno $^{20}$, esto permitirá entender que el arbitraje de inversiones en Colombia es una realidad y no una ficción limitada al ámbito académico.

\section{Acuerdos Vigentes}

El Tratado de libre comercio (TLC) entre Estados Unidos y Colombia ${ }^{21}$ contiene un capítulo $\mathrm{X}$ dedicado a la inversión, el cual contempla en la Sección $B$, los métodos de resolución de controversias. El numeral 10.16 (3) contiene una cláusula de elección múltiple para acudir al arbitraje a favor del inversionista: (i) de conformidad con el Convenio CIADI y las Reglas de Procedimiento para Procedimientos Arbitrales del CIADI, siempre que, tanto el demandado como la Parte del demandante, sean partes del Convenio del CIADI; (ii) acudir de conformidad con las Reglas del Mecanismo Complementario del CIADI $^{22}$; (iii) acudir de conformidad con las Reglas

20 La información que se incluye a continuación toma en cuenta los tratados suscritos o entrados en vigor en Colombia hasto junio de 2013 tomando como base la información suministrada en la página de internet del Ministerio de Comercio, Industria y Turismo, y la página de la Cancillería del Ministerio de Relaciones Exteriores.

21 TLC Estados Unidos-Colombia. El proceso de incorporación a la legislación interna colombiana se surtió mediante la aprobación de la Ley 11432007 por el Congreso colombiano, y se complementó mediante Sentencia C-750/08 de la Corte Constitucional mediante la cual el Acuerdo y la citada ley se encontraron acordes al ordenamiento constitucional del país. El proceso culminó con la publicación del Decreto 993 del 15 de mayo de 2012, mediante el cual se promulgó el "Acuerdo de promoción comercial entre la República de Colombia y los Estados Unidos de América", sus "Cartas Adjuntas" y sus "Entendimientos". http:// www.tlc.gov.co/publicaciones.php?id=14853

22 Reglamento del Mecanismo Complementario del CIADI. Adoptado el 27/9/1978 por el Consejo Administrativo del CIADI. 
de Arbitraje de la CNUDMI o; (iv) si el demandante y el demandado lo acuerdan, ante cualquier otra institución de arbitraje o bajo cualquiera otras reglas de arbitraje $\mathrm{e}^{23}$.

El Tratado de Libre Comercio entre los Estados Unidos Mexicanos y la República de Colombia ${ }^{24}$, y el Acuerdo de Promoción Comercial entre la República de Colombia y Canadá25, contienen un capítulo dedicado a la inversión en donde el inversionista puede escoger entre: (i) el arbitraje CIADI, de conformidad con las Reglas de Procedimiento para Procedimientos Arbitrales del CIADI; (ii) el arbitraje de conformidad con las Reglas del Mecanismo Complementario del CIADI

Introducción "El Consejo Administrativo del Centro adoptó el Reglamento del Mecanismo Complementario autorizando al Secretariado del CIADI a administrar cierta categoría de procedimientos entre Estados y nacionales de otros Estados que están fuera del ámbito de aplicación del Convenio del CIADI Estos son: (i) procedimientos de comprobación de hechos; (ii) procedimientos de conciliación o arbitraje para el arreglo de diferencias relativas a inversiones que surjan entre partes, una de las cuales no sea un Estado Contratante o un nacional de un Estado Contratante; y (iii) procedimientos de conciliación o arbitraje entre partes, de las cuales al menos una sea un Estado Contratante o un nacional de un Estado Contratante, para el arreglo de diferencias que no surjan directamente de una inversión, a condición de que la transacción en cuestión no sea una transacción comercial ordinaria".

23 Un estudio de la embajada americana señala quela celebración de tratados de inversión y de tratados de libre comercio en Colombia incrementará los arbitrajes internacionales de inversión. Por regla general, el ejercicio de los poderes excepcionales del Estado no pueden ser sometidos a arbitraje. Sin embargo, el ejercicio de estos poderes podría ser considerado como una violación a los términos del tratado dándole competencia al tribunal internacional para pronunciarse sobre ellos. US. Embassy - Bogotá Colombia. Op. cit., p.9.

24 El TLC México-Colombia-Venezuela se firmó el 13 de junio de 1994 y entró en vigor el 1 de enero de 1995, mediante la Ley de la República de Colombia No. 172 de 1994. Venezuela presentó formalmente la denuncia al Acuerdo en mayo de 2006, la cual surtiría efecto a los 180 días de la notificación a las Partes y a la Secretaría General. En el momento de entrar en vigencia e tratado en Colombia, Colombia no hacia parte de la Convención de Washington. Mirar artículo 17-18. https://www.mincomercio. gov.co/mincomercioexterior/publicaciones.php?id=1847. Nota: México no hace parte de la Convención de Washington.

25 El Acuerdo de Promoción Comercial entre la República de Colombia y Canadá, sus cartas adjuntas y sus entendimientos fueron suscritos en Lima, Perú, el 21 de noviembre de 2008, y "el canje de notas que corrige el acuerdo de libre comercio entre Colombia y Canadá" el 18 y 20 de febrero de 2010. El acuerdo fue aprobado mediante la Ley 1363 del 9 de diciembre de 2009 por el Congreso colombiano. El proceso de incorporación a la legislación interna colombiana se complementó el 24 de julio de 2010, cuando la Corte Constitucional mediante sentencia C-608/10 encontró acorde al ordenamiento constitucional del país a este Acuerdo, así como la Ley 1363 de 2009, aprobatoria del mismo. De igual manera el acuerdo fue aprobado en consenso por el parlamento canadiense el 21 de junio de 2010, y posteriormente firmado por la gobernadora general de este país. El acuerdo entró en vigor el 15 de agosto de 2011. Mirar artículo 822. http://www.tlc.gov.co/publicaciones.php?id=16157 y, (iii) arbitraje de conformidad con las Reglas de Arbitraje de la CNUDMI.

El Tratado de Libre Comercio entre Colombia, El Salvador, Guatemala y Honduras ${ }^{26}$; el Acuerdo de Libre Comercio entre Chile y Colombia ${ }^{27}$; y el Convenio sobre promoción y protección recíproca de inversiones entre Colombia y Perú ${ }^{28}$ contienen un capítulo de inversión en donde el inversionista puede escoger en caso de conflicto entre: (i) un arbitraje ad hoc bajo las reglas del CNUDMI, (ii) el arbitraje CIADI, (iii) el arbitraje de conformidad con las Reglas del Mecanismo Complementario del CIADI y, (iv) un tribunal de arbitraje bajo otra institución de arbitraje o bajo otras reglas de arbitraje, acordadas por las partes.

El Acuerdo de Promoción y Protección recíproca de inversiones entre el Reino de España y la República de Colombia ${ }^{29}$; el Acuerdo Bilateral para la Promoción y Protección de Inversiones entre el Gobierno de la República de Colombia y el Gobierno de la República Popular de China ${ }^{30}$; y el

26 El TLC Colombia-El Salvador-Guatemala-Honduras fue firmado el 9 de agosto de 2007 en Medellín Colombia, radicado en el Congreso colombiano en febrero 20 de 2008 quien lo ratificó el 3 de junio. Obtuvo sanción presidencial el 30 de julio de 2008 con Ley 1241. Fue declarado exequible por la Corte Constitucional, el 8 de julio con Sentencia C-446 de 2009, que se notificó el 23 de septiembre de 2009. Mirar artículo 12.18. http://www.tlc.gov. co/publicaciones. php?id=14515

27 Acuerdo de Libre Comercio entre Chile y Colombia. El Acuerdo de Libre Comercio entre los Gobiernos de la República de Colombia y la República de Chile, suscrito el 27 de noviembre de 2006, entró en vigor el 8 de mayo de 2009. El Acuerdo de Libre Comercio entre los Gobiernos de la República de Colombia constituye un Protocolo Adicional al Acuerdo de Complementación Económica ACE No. 24 suscrito entre Colombia y Chile, el 6 de diciembre de 1993. Derivado del ACE No. 24 en desarrollo a lo establecido en el artículo 20, Capítulo X, Colombia y Chile suscribieron el Acuerdo para la Promoción y Protección Recíproca de las Inversiones, el 20 de enero de 2000. Mirar artículo 9.16. http://www.tlc.gov.co/ publicaciones. php?id=5398

28 El Acuerdo sobre promoción y protección recíproca de inversiones entre Perú y Colombia entró en vigencia el 30 de diciembre de 2010. Sentencia de Constitucionalidad C-008 de 1997 y C-961 de 2003. Mirar artículo 20. http://unctad.org/ Sections/dite_pcbb/docs/bits_colombia.pdf

29 Acuerdo entre el Reino de España y la República de Colombia para la promoción y protección recíproca de inversiones entró en vigencia el 22 de septiembre de 2007. Sentencia de Constitucionalidad C-309 de 2007. Mirar artículo 10. https:// www.mincomercio.gov.co/mincomercioexterior/publicaciones. php?id=1847

30 Acuerdo Bilateral para la Promoción y Protección de Inversiones entre el Gobierno de la República de Colombia y el Gobierno de la República Popular de China. Firmado en Lima, Perú, el 22 de noviembre de 2008. Aprobado por la Ley 1462 DE 2011 y entró en vigor el 2 de julio de 2012. Ver Sentencia C-199 de 2012. Mirar artículo 9. http://www.unctadxi.org/templates/ DocSearch.aspx?id=779 
Acuerdo para la Promoción y Protección reciproca de inversiones entre Colombia y la República de la India ${ }^{31}$, prevén que en caso de controversia, y bajo el respeto de otras reglas propias a cada uno de estos Acuerdos, podrá someterse, a elección del inversionista a: (i) los tribunales competentes de la Parte Contratante en cuyo territorio se realizó la inversión; (ii) un tribunal de arbitraje ad hoc establecido de acuerdo con el Reglamento de Arbitraje de la Comisión de las Naciones Unidas para el Derecho Comercial Internacional; o (iii) el Centro Internacional de Arreglo de Diferencias Relativas a Inversiones (CIADI), creado por el Convenio sobre el arreglo de diferencias relativas a inversiones entre Estados y Nacionales de Otros Estados, cuando ambos Estado hagan parte del Acuerdo; (iv) en caso de que una de las Partes Contratantes no fuera Estado Contratante del citado Convenio, la controversia se podrá resolver conforme al Mecanismo Complementario para la Administración de Procedimientos de Conciliación, Arbitraje y Comprobación de Hechos por la Secretaría del CIADI. En el caso del Acuerdo con China no se hace mención expresa a la CNUDMI. En el caso de India, se prevé adicionalmente la posibilidad de conciliación bajo las reglas de la CNUDMI.

El Acuerdo de Promoción y Protección reciproca de inversiones entre la Confederación Suiza y Colombia ${ }^{32}$ prevé, en el artículo 11, la Resolución de Disputas entre una Parte y un Inversionista de la otra Parte. En caso de conflicto, el inversionista tendrá la opción de escoger entre: (i) El Centro Internacional de Arreglo de Diferencias Relativas a Inversiones (CIADI) $y$, (b) un tribunal ad-hoc que, a menos que exista un acuerdo distinto entre las partes de la disputa, deberä establecerse bajo el Reglamento de Arbitraje de la Comisión de las Naciones Unidas para el Derecho Mercantil Internacional (CNUDMI)".

31 Acuerdo para la Promoción y Protección reciproca de inversiones entre Colombia y la República de la India suscrito en la ciudad de Nueva Delhi, el día 10 de noviembre de 2009, entró en vigor el 2 de julio de 2012. Mirar artículo 9. http://www. unctadxi.org/templates/DocSearch.aspx?id=779

32 Acuerdo de Promoción y Protección reciproca de inversiones entre la Confederación Suiza y Colombia entró en vigor el 6 de octubre de 2009. Sentencia de Constitucionalidad C-150 de 2009. https://www.mincomercio.gov.co/mincomercioexterior/ publicaciones.php?id=1847

\section{ACUERDOS SUSCRITOS}

El Acuerdo de Libre Comercio suscrito entre Colombia y la República de Corea contempla la manera de presentar una reclamación en caso de conflicto. El Acuerdo prevé que la demanda podrá ser presentada, a elección del inversionista ante:

(a) cualquier tribunal competente o tribunal administrativo de la Parte contendiente; o (b) arbitraje de conformidad con esta Sección bajo: (i) el Convenio del CIADI, si el Convenio del CIADI está disponible; (ii) el Reglamento del Mecanismo Complementario del CIADI, si el Reglamento del Mecanismo Complementario del CIADI está disponible; (iii) las Reglas de Arbitraje de la CNUDMI; o (iv) si así lo acuerdan ambas partes contendientes, cualquier otra institución de arbitraje o bajo cualquier otras reglas de arbitraje. (negrilla fuera del original) ${ }^{33}$

El Acuerdo para la Promoción y Protección Recíproca de Inversiones suscrito entre el Reino Unido y Colombia ${ }^{34}$; el Acuerdo para la Promoción y Protección Recíproca de inversiones entre Japón y Colombia ${ }^{35}$; el Acuerdo entre Colombia y la Unión Económica Belgo-Luxemburguesa para la Promoción y Protección Reciproca de Inversiones $^{36}$; y el Acuerdo de Libre Comercio entre la República de Colombia y la República de Costa Rica ${ }^{37}$, tienen en común que el inversionista

33 Acuerdo entre Colombia y la República de Corea suscrito el 21 de febrero de 2013. En aprobación de congreso. Mirar artículo 8.18. http://www.tlc.gov.co/publicaciones.php?id=6421

34 Acuerdo para la Promoción y Protección Recíproca de Inversiones suscrito entre el Reino Unido Gran Bretaña e Irlanda del norte y la República de Colombia. APPRI firmado el 17 de Marzo de 2010. Presentado al Congreso. Proyecto de Ley 253 de 2010 (Senado). Ley 1464 de 2011. Aprobado Corte Constitucional $C$-169 de 2012. De acuerdo con nuevo reglamento de la UE, Reino Unido solicitó autorización a la Comisión para implementar el APPRI con Colombia en enero de 2013, la Comisión tiene 6 meses para pronunciarse. Mirar artículo IX. http://www.tlc.gov.co/ publicaciones. php?id=6421

35 Acuerdo para la Promoción y Protección Recíproca de inversiones entre Japón y Colombia. Negociación finalizada en diciembre de 2010 en Washington D.C. Suscrito el 12 de septiembre de 2011. Se presentó al congreso en la primera semana de septiembre de 2012. Fue probado en primer debate Comisión II Senado. Pendiente Plenaria de Senado. Mirar Capítulo III, artículo 27 (5) http://unctad.org/Sections/ dite_pcbb/docs/bits_colombia.pdf y http://www.tlc.gov.co/ publicaciones. php?id=6421

36 Acuerdo entre Colombia y la Unión Económica BelgoLuxemburguesa. Firmado en Bruselas, Bélgica el 4 de febrero de 2009 y en trámite legislativo en el Congreso de la República. Mirar artículo XII. http://www.cancilleria.gov.co/footer/ juridicainternacional/tratados/inversion/suscritos

37 Acuerdo de Libre Comercio entre la República de Colombia y 
puede referir la controversia, a su elección, a: (i) El CIADI; (ii) el Mecanismo Complementario para la Administración de Procedimientos de Conciliación, Arbitraje y Comprobación de Hechos; (iii) un tribunal de arbitraje de conformidad con las Reglas de la CNUDMI. En el caso del Acuerdo con el Reino Unido se encuentra adicionalmente: (i) un tribunal conformado de acuerdo con las Reglas de Arbitraje de la institución de arbitraje de la Parte Contratante en cuyo territorio se realizó la inversión o (ii) la Cámara de Comercio Internacional (CCI). En el caso del Acuerdo con Japón y el de Costa Rica se encuentra, además, cualquier arbitraje de acuerdo con otras reglas de arbitraje, incluyendo una institución de arbitraje ad hoc. Finalmente, en el caso del Acuerdo con la Unión Económica BelgoLuxemburguesa, encontramos adicionalmente a la CCI o un tribunal de arbitramento del Centro de conciliación y Arbitraje de la Cámara de Comercio de Bogotá.

Respecto del Acuerdo Comercial suscrito entre la Unión Europea, Colombia y Perú ${ }^{38}$, el Acuerdo no prevé el método de resolución de conflictos para los inversionistas en caso de violaciones al Acuerdo, pero contempla la creación de un “Comité de Comercio" y la conformación de lo que denomina un "Grupo Arbitral" en caso de conflicto entre las partes contratantes del Acuerdo ${ }^{39}$. El Comité de Comercio está regulado en el Título II y estará compuesto por representantes de la Parte UE, y representantes de cada País Andino signatario y tiene entre sus funciones: Adoptar las Reglas de Procedimiento y el Código de Conducta para los árbitros, establecer la remuneración y los gastos que se pagarán a los árbitros, recibir copia de la comunicación de inicio de consultas en caso de conflicto, recibir igualmente la solicitud de

la República de Costa Rica. Las negociaciones para un TLC con Costa Rica iniciaron a finales de junio de 2012. El Acuerdo se suscribió el 22 de mayo de 2013. Mirar artículo 12.17. http:// www.tlc.gov.co/publicaciones.php?id=3432 y https://www. mincomercio.gov.co/publicaciones. php?id=6584

38 Acuerdo Comercial entre Colombia, Perú y la Unión Europea suscrito el 26 de junio de 2012. http://www.tlc.gov.co/ publicaciones. php?id=6421

39 Los inversionistas no entrarían en la definición de "Parte" del Acuerdo. Según el artículo 6 del Acuerdo se entiende por "Parte" la Unión Europea o sus Estados Miembros o la Unión Europea y sus Estados Miembros en el marco de sus respectivos ámbitos de competencia derivados del Tratado de la Unión Europea y del Tratado de Funcionamiento de la Unión Europea, o cada uno de los Países Andinos signatarios;... - «Partes» significa, por un lado, la Parte UE y, por otro lado, cada uno de los Países Andinos signatarios. establecimiento del grupo arbitral, y cumplir, de manera general, las funciones de organización y administración del procedimiento arbitral.

Además de los acuerdos suscritos y los acuerdos vigentes, Colombia está en proceso de negociación para la conclusión de más acuerdos con Panamá, Turquía, Japón ${ }^{40}$, Israel, Rusia y la Alianza del Pacifico. Sin lugar a dudas el arbitraje internacional de inversiones llega a Colombia, sin embargo, las ventajas e inconvenientes de este nuevo sistema tienen que sopesarse para entender el verdadero impacto en la realidad jurídica nacional.

\subsection{Las ventajas para Colombia de los tratados y el arbitraje de inversiones}

La celebración de tratados se ha impuesto como un nuevo método para los países en desarrollo para atraer inversión extranjera sobre el territorio gracias a los estándares de protección acordados a los inversionistas. El arbitraje, comprendido en la mayoría de los textos de estos instrumentos internacionales, es una garantía más a favor de los inversionistas, como mínimo de seguridad sobre la inversión en el territorio en caso de violación a los términos pactados. No se pretende tratar la totalidad de ventajas de los tratados y del arbitraje de inversiones, sino dar una visión general de las virtudes que le han sido atribuidas.

\subsubsection{Las ventajas proporcionadas por los tratados}

La seguridad jurídica, que proporciona los tratados, incentivaría a los inversionistas a invertir en el Estado receptor de la inversión al crearse un "ambiente de inversión favorable". El solo hecho de que se contemplen métodos eficaces de solución de conflictos, y no necesariamente su uso, incentivaría la inversión ${ }^{41}$. Existen muchas discusiones sobre la verdadera relación entre tratados de inversión y el aumento de la inversión extranjera en el país receptor de la inversión. En 1997, el Profesor Andrew Guzman ponía en

40 Acuerdo de Asociación Económica entre Colombia y Japón. Las negociaciones para un AAE con Japón iniciaron formalmente en diciembre de 2012, previo a lo cual ambos países adelantaron un estudio conjunto sobre la posibilidad de adelantar dicho proceso. http://www.tlc.gov.co/publicaciones.php?id=3965

41 Dispute Settlement. International Center for Settlement of Investment Disputes. New York y Ginebra. (2003). United Nations Conference on Trade and Development, p. 16-17. 
duda los verdaderos efectos de la celebración de tratados en el crecimiento de la inversión extranjera en los países "menos desarrollados". De esta forma señaló que los tratados incrementan la eficacia y reducen el costo de la inversión extranjera, pero eso no significa que traigan beneficios a los países en desarrollo, considerados como grupo. El hecho de que un país en desarrollo celebre un tratado implica que otros países en desarrollo pierdan inversión. La lucha separada de los países en desarrollo termina por disminuir la rentabilidad de la inversión del conjunto de países desarrollados, por lo cual estos deberían dejar de concluir tratados y de competir el uno contra el otro ${ }^{42}$.

En junio del 2003 un estudio de Mary Hallward-Driemeier, del Banco Mundial, llegó a la conclusión de que los tratados de inversión por sí solos no incentivan la inversión. Las circunstancias internas del país cuentan también, si las instituciones estatales a nivel interno son débiles, el inversionista no va a querer venir al Estado, aunque exista un tratado de inversión. Existen costos que muchas veces no son evaluados, prudentemente, por los gobiernos después de la firma de un tratado y que tienen que ver con los montos de las eventuales demandas contra el Estado ante un tribunal internacional: lo cual puede representar la dificultad en el cambio de políticas públicas futuras, que pueden traducirse en demandas para el Estado sobre la base de la violación de un tratado ${ }^{43}$. En el mismo año Jennifer Tobin y Susan RoseAckerman publicaron otro estudio y la conclusión fue parcial. En la celebración de tratados los inversionistas extranjeros pueden percibir que el riesgo de inversión es inferior y que la protección es más fuerte. Cuando en los Estados receptores la inversión es tan solo relativamente riesgosa, los tratados traen más inversión. Respecto de los inversionistas locales o nacionales, de manera general, parece existir una relación positiva entre los tratados de inversión y la inversión privada local, los derechos concedidos a los extranjeros no parecen en realidad afectar de manera importante las inversiones locales. Los autores concluyen diciendo que, de todas maneras, la relación entre

42 GUZMAN, Andrew T. (1997-1998). Why LDC's Sign Treaties That Hurt Them : Explaining The Popularity of Bilateral Investment Treaties. EN: Berkeley Law. 38 VA J. Int'l L. 639.

43 HALLWARD-DRIEMEIER, Mary. (2003). Do Bilateral Investment Treaties Attract FDI? Only a bit... and they could bite. EN: World Bank, DECRG. los tratados y la inversión extranjera resulta "débil"44.

Por el contrario, Eric Neumayer y Laura Spess concluyeron en el 2005, que los tratados de inversión entre países en desarrollo y desarrollados sí incrementan la inversión. Después de realizar algunas críticas a otros estudios, entre los cuales están los de HallwardDriemeier, Jennifer Tobin y Susan RoseAckerman $^{45}$, afirman que los países en desarrollo que firman tratados de inversión reciben mayores flujos de inversión extranjera. Los autores señalan que lo tratados sirven como substitutos a la pobre calidad institucional del país receptor. Asimismo, los tratados pueden no incrementar los flujos de inversión extranjera cuando los riesgos en el país receptor son altos, pero eso no significa que, por eso, los tratados se traduzcan en una disminución del flujo de inversión. No obstante, es incierto si la mayor inversión extranjera compensa los mayores costos substanciales en que se incurren en la negociación: firma, conclusión de tratados, así como las estrictas obligaciones contraídas y contenidas en estos instrumentos ${ }^{46}$.

Un estudio de 2011 de Mudziviri Nziramasanga, Frederick S. Inaba y Sanatan Shreay señala, entre otras variables, que la conclusión de tratados

44 TOBIN, Jennifer \& ROSE-ACKERMAN, Susan. (2003 y 2005) Foreign Direct Investment and the Business Environment in Developing Countries: the Impact of Bilateral Investment Treaties. The William Davidson Institute at the University of Michigan Business School. Working Paper Number 587. Noviembre 13 de 2003 (actualizada el 3 de enero de 2005) p. 12 y ss. El primero de junio de 2006 TOBIN y ACKERMAN publicaron otro artículo sobre el tema en donde señalan que en realidad sí existe una relación directa entre inversión extranjera y tratados de inversión. TOBIN, Jennifer \& ROSE-ACKERMAN Susan. (2006). Bilateral Investment Treaties: Do They Stimulate Foreign Direct Investment?. Yale University. Disponible en: http://s3.amazonaws.com/zanran_storage/www.upf.edu/ ContentPages/822485.pdf

45 Susan Rose Ackerman público en el 2006, junto a Jennifer Tobin otro artículo al respecto titulado "Bilateral Investment Treaties: Do They Stimulate Foreign Direct Investment? 》 en donde afirman que los tratados de inversión tienen un impacto positivo en los flujos de inversión extranjera en los países en desarrollo. Se declararon escépticos respecto del fundamento pero resaltaron que al parecer, la firma de tratados envía una señal positiva a los inversionistas sobre la buena acogida de la inversión en el Estado receptor. Sin embargo, añaden que entre más tratados sean concluidos en el mundo, el beneficio marginal de firmar otro tratado para el Estado receptor caerá. TOBIN, Jennifer \& ROSE-ACKERMAN, Susan. (2006). Bilateral Investment Treaties: Do They Stimulate Foreign Direct Investment? Yale University. Disponible en: http://s3.amazonaws.com/zanran_ storage/www.upf.edu/ContentPages/822485.pdf

46 NEUMAYER, Eric \& SPESS, Laura. Op. cit., p. 1568-1569-15751582. 
de inversión por los países en desarrollo les da credibilidad a los gobiernos en la protección de la inversión de los inversionistas extranjeros, lo cual incrementa la inversión. La clave de la credibilidad del país receptor se encuentra, además, en las provisiones de los tratados que le otorgan el derecho al inversionista de acudir en caso de disputa a tribunales de arbitraje internacional. Sin embargo, la existencia misma de disputas ante tribunales internacionales, por violaciones a los tratados, tiene un efecto negativo debido a que puede percibirse como una falta de compromiso de honrar los términos de los tratados y convertirse en una herramienta de presión para obligar al Estado a negociar. Esto a la larga podría generar una reducción del flujo de inversión extranjera que, a juicio de los autores, no había sido considerada en otros estudios ${ }^{47}$.

Lo cierto es que la mera celebración de tratados no puede generar un incremento significativo del flujo de inversión si el país no goza de las condiciones políticas, sociales y económicas favorables tendientes a generar un ambiente propicio para la inversión. Si no existe una estructura adecuada en el Estado receptor, los tratados terminan siendo un pergamino más para archivar y un arma evidente que los inversionistas extranjeros pueden utilizar para buscar indemnizaciones por violación a los términos pactados.

Igualmente, los tratados contemplan una serie de estándares mínimos de protección de la inversión para los nacionales de los Estados signatarios. Se contemplan medidas contra la expropiación que, en caso de presentarse, debe tener una indemnización integral pronta, adecuada y efectiva, fundada en el interés público y sin tratos discriminatorios. Un tratamiento justo y equitativo sin discriminación al inversionista por parte de las autoridades locales bajo la existencia de reglas transparentes y predecibles. El principio de protección y seguridad plena para que el Estado receptor ejerza la debida diligencia para la protección de la inversión extranjera. La cláusula de la nación más favorecida, que consiste en que la inversión no puede recibir un trato menos favorable que la inversión realizada

47 NZIRAMASANGA, Mudziviri, S. INABA, Frederick \& SHREAY Sanatan. (2011). Do Bilateral Investment Treaties Deliver the Goods? Evidence from Developing Countries. Review of Applied Economics. Vol. 7, No. 1-2, p. 26 y ss. por los nacionales de otro Estado cualquiera. El tratamiento nacional para que la inversión extranjera no reciba un trato menos favorable que la inversión realizada por los nacionales del Estado receptor. El principio de libre transferencia de los fondos relacionados con la inversión, que consiste en que las transferencias relativas a una inversión se efectúen sin demora y de manera libre, para evitar el bloqueo del capital del inversionista. Estos no son los únicos estándares de protección que pueden ser pactados por las partes, aunque sí los principales. El contencioso del arbitraje de inversiones gira en torno al alcance e interpretación de estas nociones.

La conclusión de tratados de inversión, envía una señal positiva a los potenciales inversionistas extranjeros sobre la viabilidad de invertir en el Estado receptor. La conclusión de tratados no sólo incentiva a los nacionales de los Estados implicados a contemplar la idea de invertir, sino que muestra señales positivas a los nacionales de los Estados que no hacen parte de ningún acuerdo con el Estado receptor, de que la situación política, social y económica del país facilita la inversión. La existencia de tratados permite reducir las posibilidades de que la disputa se torne política. El hecho de que existan criterios objetivos en las relaciones entre las Partes al tratado facilita la resolución de conflictos que, en caso de ocurrir, serán entregados a un tribunal arbitral internacional para ser resueltos jurídicamente. Esto permite eliminar la guerra "naval" de antaño. El inversionista no tiene necesidad de pedir la intervención de su Estado de origen, lo cual evita el riesgo de encontrarse envuelto en un debate geopolítico de otro orden ${ }^{48}$. En un momento en el que la mayoría de países en el mundo entero compiten por atraer la inversión extranjera, la celebración de tratados permite entrar en una competencia directa con otras Naciones con una larga tradición de celebración de estos instrumentos. La conclusión de tratados permitiría competir en mayor igualdad con otros países en desarrollo.

Por último, al inversionista no solo le interesa que su inversión esté protegida en los tratados sino que, en caso de violación a los términos del tratado, pueda acudir directamente a un tribunal imparcial y especializado que lo ayude

48 Dispute Settlement. International Center for Settlement of Investment Disputes. Op. cit., p. 14 
a dirimir la controversia. La sola existencia de métodos alternativos de resolución de conflictos en los tratados representa una ventaja para los inversionistas a la hora de decidir invertir en un país.

\subsubsection{Las ventajas del arbitraje internacional de inversiones previstas en los tratados: El caso del CIADI}

El arbitraje contemplado en los tratados goza de numerosas ventajas para los inversionistas y constituye una muestra de buena fe por parte del Estado, con respecto a su disposición para renunciar a su jurisdicción local, en beneficio de un tribunal internacional. Esto muestra al inversionista la voluntad del Estado de acoger la inversión y de proporcionarle garantías para ser tratado con justicia e imparcialidad.

Además, los inversionistas no estarían obligados a acudir a las cortes nacionales del país receptor de la inversión, a no ser que el tratado lo prevea. Igualmente, el inversionista no dependería de la voluntad de su país de origen de ejercer la protección diplomática en su defensa. El inversionista cuenta con la posibilidad de entrar en negociaciones directas con el Estado en caso de violación a los estándares de protección y, de no llegar a un acuerdo, de demandar directamente al Estado ante un tribunal internacional de inversiones.

La Convención de Washington, en la etapa de reconocimiento, se caracteriza por las ventajas y atractivos para los intervinientes, en especial para los inversionistas. Ninguna de las excepciones para otorgar el reconocimiento de un laudo arbitral contempladas en la Convención de New York se encuentran disponibles en la Convención de Washington. El reconocimiento de un laudo consiste en darle un valor vinculante y definitivo a la decisión, el propósito es confirmar el efecto de res judicata del laudo, establecer que los asuntos resueltos en el laudo no podrán ser reexaminados. La ejecución corresponde a un procedimiento distinto, y posterior, al reconocimiento del laudo, que bajo el CIADI opera de manera automática. Parte de la doctrina divide el procedimiento, tendiente a la ejecución de un laudo arbitral, en tres momentos distintos. Primero, la etapa de reconocimiento del laudo (i), acto seguido, el proceso de exequátur (ii) (en los casos en que el ordenamiento jurídico del país en donde se busca ejecutar la sentencia lo requiera) y, finalmente, la etapa de ejecución (iii). El exequátur otorga la fuerza ejecutoria al laudo para poder perseguir los activos de la parte que haya sucumbido en el arbitraje $\mathrm{e}^{49}$, sin embargo, bajo el sistema CIADI, no se requiere de un exequátur para buscar la ejecución del laudo arbitral.

En el contexto de un arbitraje CIADI, la ejecución se confunde generalmente con el reconocimiento. Uno de los puntos más fuertes del Convenio CIADI, es el hecho de no aceptar argumentos tendientes a rechazar el reconocimiento de laudos arbitrales extranjeros. Los tribunales nacionales deben reconocer inmediatamente el laudo, como si fuera una sentencia nacional emitida por un tribunal local. La parte que busque el reconocimiento y ejecución del laudo solo necesitará presentar una copia certificada del laudo a la autoridad competente. La autoridad designada sólo podrá verificar la autenticidad del laudo arbitral.

El artículo $54(1)^{50}$ del Convenio CIADI distingue las obligaciones pecuniarias de las no pecuniarias e impone un reconocimiento automático -mas no ejecución- de las obligaciones no pecuniarias, dejando probablemente tales laudos a la ejecución prevista bajo la Convención de Nueva York, en caso de que esta última sea aplicable. En caso de obligaciones pecuniarias reconocidas por el laudo, los Estados-Parte deben ejecutar el laudo dentro de su territorio como si fuera una sentencia de un tribunal nacional. Dado este tratamiento distinto entre obligaciones pecuniarias y no pecuniarias, las partes deben considerar tratar todas sus pretensiones como obligaciones pecuniarias ${ }^{51}$.

49 LINETSKY Andrés Jana \& KLEIN KRANENBERG, Johanna. (2008). La convención de Nueva York y el CIADI Reconocimiento y Ejecución de Laudos Arbitrales bajo la Convención de Washington. EN: Abeledo Perrot (Ed.). El Arbitraje Comercial Internacional, Estudio de la Convención de Nueva York con motivo de su $50^{\circ}$ aniversario. Tawil, Guido Santiago \& Zuleta, Eduardo. Buenos Aires.

50 Convenio CIADI, Artículo 54 (1) "Todo Estado Contratante reconocerá al laudo dictado conforme a este Convenio carácter obligatorio y hará ejecutar dentro de sus territorios las obligaciones pecuniarias impuestas por el laudo como si se tratare de una sentencia firme dictada por un tribunal existente en dicho Estado. El Estado Contratante que se rija por una constitución federal podrá hacer que se ejecuten los laudos a través de sus tribunales federales y podrá disponer que dichos tribunales reconozcan al laudo la misma eficacia que a las sentencias firmes dictadas por los tribunales de cualquiera de los estados que lo integran".

51 REED, Lucy; PAULSSON, Jan; y BLACKABY, Nigel. (2004). Guide 
Las partes pueden atacar el laudo basados en causales limitativas que se encuentran en la Convención de Washington. Es pertinente aclarar que el proceso aplica para los laudos dictados bajo la Convención y no para los laudos dictados bajo el Reglamento del Mecanismo Complementario del CIADI $^{52}$, o las reglas de la Comisión de las Naciones Unidas para el Derecho Mercantil Internacional (CNUDMI), administradas por el CIADI. Los laudos emitidos bajo estas dos últimas categorías no son firmes y vinculantes, y están gobernados por las reglas de la Convención de Nueva York ${ }^{53}$. Dicho de otra manera, pueden ser anulados por tribunales nacionales del Estado en donde se llevó a cabo el arbitraje. En estos casos, las partes tienen normalmente la posibilidad de atacar el laudo ante los tribunales del Estado, y quien quiera ejecutar el laudo por fuera del territorio del Estado-parte, estará sometido a un control de la decisión según las reglas en vigor en el correspondiente Estado ${ }^{54}$.

Las partes bajo el Convenio CIADI solo pueden buscar la revisión del laudo en caso de que este sea definitivo. El artículo 53(1) dispone que el laudo solo podrá ser objeto de los recursos establecidos por el Convenio y que sólo las partes están obligadas por la decisión CIADI, no los

to ICSID Arbitration. London. EN: Kluwer Law International, p. 106

52 Reglamento del Mecanismo Complementario del CIADI Adoptado el 27/9/1978 por el Consejo Administrativo del CIADI Introducción "El Consejo Administrativo del Centro adoptó el Reglamento del Mecanismo Complementario autorizando al Secretariado del CIADI a administrar cierta categoría de procedimientos entre Estados y nacionales de otros Estados que están fuera del ámbito de aplicación del Convenio del CIADI. Estos son: (i) procedimientos de comprobación de hechos; (ii) procedimientos de conciliación o arbitraje para el arreglo de diferencias relativas a inversiones que surjan entre partes, una de las cuales no sea un Estado Contratante o un nacional de un Estado Contratante; y (iii) procedimientos de conciliación o arbitraje entre partes, de las cuales al menos una sea un Estado Contratante o un nacional de un Estado Contratante, para el arreglo de diferencias que no surjan directamente de una inversión, a condición de que la transacción en cuestión no sea una transacción comercial ordinaria".

53 El artículo 1 (1) de la Convención de Nueva York dispone que la Convención es aplicable a las sentencias "que tengan su origen en diferencias entre personas naturales o jurídicas". El texto no formula limitaciones a las relaciones de derecho privado, de esta manera, la presencia de un ente estatal no constituye una razón para descartar la aplicación de la Convención. Algunos acuerdos bilaterales prevén la ejecución de los laudos conformemente a la Convención de Nueva York.

54 AUDIT, Bernard. (2010). Reconnaissance et exécution des sentences arbitrales hors CIRDI. EN: L.G.D.J. (Ed.), La Procédure Arbitrale Relative aux Investissements Internationaux. Bélgica. p. 248-249 terceros $^{55}$. Ahora bien, no todas las decisiones CIADI son laudos arbitrales. Según el artículo 48(3), un laudo será definitivo si trata todas las cuestiones sometidas al tribunal arbitral: Artículo 48(3): "El laudo contendrá declaración sobre todas las pretensiones sometidas por las partes al Tribunal y será motivado".

El Convenio contempla tres remedios posibles tras el fallo del tribunal arbitral: la interpretación, la revisión y la nulidad. El artículo 50 del Convenio CIADI permite a las partes pedir al Secretario General una interpretación del alcance del fallo arbitral. Interpretación que no significa revisión del fondo del laudo. Dicho Convenio no establece un periodo límite para que las partes presenten su solicitud de interpretación.

El artículo 51 permite a las partes solicitar una revisión del laudo. La única hipótesis es la existencia de pruebas documentales que puedan afectar de manera decisiva el fallo arbitral. La persona que solicita la revisión debe mostrar que el hecho es nuevo, que no era de conocimiento del tribunal arbitral, o del solicitante, y que la ignorancia de este último no tiene como origen su negligencia. El Secretario remitirá, en la medida de lo posible, la solicitud al tribunal arbitral, y si este ya ha sido disuelto, se constituirá un nuevo tribunal.

Respecto de la anulación, la particularidad es que la solicitud de anulación se somete a un Comité ad-hoc de tres miembros, constituido exclusivamente para ese propósito. Si la solicitud es acogida favorablemente, llevará a la invalidez del laudo (o algunas de sus partes), pero nunca a una corrección. La anulación le da una segunda oportunidad a las partes para acudir al arbitraje ante un tribunal arbitral CIADI completamente nuevo. El Comité ad-hoc no tiene competencia para revisar el fondo del laudo, las causales de nulidad se limitan a las del articulo $52(1)^{56}$ del

55 Convenio CIADI, articuló 53 (1): El laudo será obligatorio para las partes y no podrá ser objeto de apelación ni de cualquier otro recurso, excepto en los casos previstos en este Convenio. Las partes lo acatarán y cumplirán en todos sus términos, salvo en la medida en que se suspenda su ejecución, de acuerdo con lo establecido en las correspondientes cláusulas de este Convenio.

56 Convenio CIADI, Artículo 52 (1) "Cualquiera de las partes podrá solicitar la anulación del laudo mediante escrito dirigido al Secretario General fundado en una o más de las siguientes causas: (a) que el Tribunal se hubiere constituido incorrectamente; (b) que el Tribunal se hubiere extralimitado manifiestamente en sus facultades; (c) que hubiere habido corrupción de algún miembro del Tribunal; (d) que hubiere quebrantamiento grave de una 
Convenio CIADI. El Comité ad-hoc previsto en el Convenio no es una instancia de apelación; sin embargo, estos Comités pueden llegar a ejercer un control mucho más importante que un simple control externo. Los tribunales nacionales de los países partes, no pueden anular el laudo arbitral ya que está sometido al Convenio CIADI y no a la ley nacional.

El mecanismo establecido por la Convención de Washington, coloca al laudo arbitral en igualdad de condiciones respecto de una sentencia definitiva de un tribunal nacional. Si la sentencia nacional puede ser ejecutada, el laudo arbitral también podrá ser ejecutado. De esta manera, el Convenio no obliga al Estado-parte a ejecutar un laudo CIADI en casos en que una sentencia definitiva equivalente, y emanada de sus propios tribunales nacionales, no pueda ser ejecutada. En conclusión, los tribunales nacionales deben reconocer y ejecutar los laudos arbitrales CIADI de manera automática, pero pueden ejecutarlos de acuerdo a su propia ley nacional.

Otro de los atractivos del arbitraje de inversiones radica en que es una justicia especializada, expedita e imparcial. Se arguye que la jurisdicción local es muy demorada y en ocasiones existen problemas de independencia e imparcialidad y hasta de corrupción. El inversionista no estaría en igualdad de condiciones para presentar sus argumentos, solicitar la práctica de pruebas o defender sus puntos de vista. Se parte del hecho de que al ser ajenos a las jurisdicciones nacionales, los árbitros pueden ser neutrales e independientes en la toma de sus decisiones, esto sin contar con que son especialistas en el derecho internacional, lo cual les daría las herramientas para tomar decisiones acordes a las expectativas de las partes. La garantía de neutralidad y independencia decisoria es una ventaja para los inversionistas que no confían en el sistema local, o cuando la jurisdicción interna no tiene una verdadera experiencia en el derecho internacional $^{57}$. Sin embargo, hacer afirmaciones generales sobre la falta de objetividad del sistema judicial local puede parecer un poco apresurado y a veces alejado de la realidad. Aun en casos en que el sistema judicial local cumple todas las garantías

norma de procedimiento; o (e) que no se hubieren expresado en el laudo los motivos en que se funde".

57 Dispute Settlement. International Center for Settlement of Investment Disputes. Op. cit., p.15. de igualdad que podría esperar un inversionista, los tratados suelen excluir sistemáticamente la posibilidad de agotar los recursos internos del país receptor de la inversión.

En la segunda parte de este artículo se tratarán los desafíos del Arbitraje de Inversiones y las reacciones que se vienen dando en el mundo respecto de su funcionamiento.

2. Las consecuencias de este nuevo arbitraje y los inconvenientes que debe tener en cuenta el gobierno colombiano

La forma en que está concebido el arbitraje internacional de inversiones parece en principio ser una solución ideal para los conflictos entre Estados y nacionales de otros Estados bajo un Acuerdo de inversión. Sin embargo, la práctica refleja que en ocasiones no existe un adecuado balance de intereses entre el inversionista y el Estado. Las reacciones y críticas al arbitraje de inversiones en el mundo deben ser examinadas con el objetivo de comprender lo que puede representar para el país.

En esta segunda parte se abordarán dos temas principales: (2.1) Las críticas al arbitraje de inversiones. Identificar la enfermedad puede servir a prevenirla, combatirla o anticiparla, esta es la razón de analizar las críticas y cuestionamientos que ha presentado el sistema. (2.2) Por otro lado, resulta imprescindible identificar las principales herramientas para la viabilidad del sistema. Los Estados deben mantener comportamientos responsables en las fases de negociación de los términos de los tratados y en la coordinación de las entidades estatales sobre las políticas internacionales para que la instancia arbitral recupere su fuerza. Cuando los árbitros entienden con claridad lo pactado por las Partes se limita la posibilidad de largas y oscuras interpretaciones por parte de los tribunales.

\subsection{Desafíos y críticas que ha recibido el} sistema

El arbitraje internacional de inversiones pactado en los tratados, y el CIADI como Centro más influyente en la resolución de conflictos de este género, vive un momento agitado. En efecto, se puede apreciar un movimiento mundial que ha ido creciendo con el tiempo y que busca quitarle legitimidad al sistema concebido por la Convención de Washington. Las dificultades de 
modificación de la Convención de Washington como solución a los cuestionamientos que plantea el sistema nos llevan a buscar otros caminos. El árbitro de inversiones toma su decisión basado en los términos de los tratados, de ahí la importancia de efectuar negociaciones responsables de los estándares de protección y de la definición de la inversión que debe ser protegida. Asimismo, el Estado debe utilizar todas las herramientas a su favor para evitar llegar a la instancia arbitral: conciliar es mejor que litigar.

\subsubsection{Movimiento en contra del arbitraje de} inversiones

El sistema de arbitraje de inversiones viene siendo cuestionado hace unos años, en gran parte por los países en vía de desarrollo, que han visto sus intereses en juego ante instancias internacionales de inversiones. De esta manera Bolivia denunció y se retiró de la Convención de Washington en el 2007, Ecuador en el año 2010 y Venezuela en el $2012^{58}$. La India ${ }^{59}$ y Brasil no

58 Centro Internacional de Arreglo de Diferencias Relativas a Inversiones -CIADI-. Lista de Estados Contratantes y Signatarios del Convenio (al 20 de mayo de 2013). "El Gobierno de la República de Bolivia firmó el Convenio del CIADI el 3 de mayo de 1991 y depositó su instrumento de ratificación el 23 de junio de 1995. El Convenio entró en vigor para Bolivia el 23 de julio de 1995. El 2 de mayo de 2007, el depositario recibió una notificación por escrito de la denuncia de Bolivia del Convenio De conformidad con el Artículo 71 del Convenio, la denuncia produjo efecto seis meses después del recibo de la notificación de Bolivia, es decir el 3 de noviembre de 2007. El Gobierno de la República del Ecuador firmó el Convenio del CIADI el 15 de Enero de 1986 y depositó su instrumento de ratificación en la misma fecha. El Convenio entró en vigor para el Ecuador el 14 de febrero de 1986. El 6 de julio de 2009, el depositario recibió una notificación por escrito de la denuncia del Ecuador del Convenio De conformidad con el Artículo 71 del Convenio, la denuncia produjo efecto seis meses después del recibo de la notificación del Ecuador, es decir el 7 de enero de 2010. El Gobierno de la República Bolivariana de Venezuela firmó el Convenio del CIADI el 18 agosto de 1993 y depositó su instrumento de ratificación el 2 mayo de 1995. El Convenio entró en vigor para la República Bolivariana de Venezuela el 1 junio de 1995. El 24 de enero de 2012, el depositario recibió una notificación por escrito de la denuncia de la República Bolivariana de Venezuela del Convenio. De conformidad con el Artículo 71 del Convenio, la denuncia produjo efecto seis meses después del recibo de la notificación de la República Bolivariana de Venezuela, es decir el 25 de julio de 2012". https://icsid.worldbank.org/ICSID/FrontServlet?requ estType $=I C S I D D o c R H \&$ action Val $=$ ShowDocument\&language $=S$ panish

59 La India es uno de los países con mayor inversión extranjera. Sin embargo, no hace parte del CIADI ya que consideró que sería conceder parte de su soberanía. En los años sesenta, cuando la Convención de Washington fue adoptada, la India no estaba económicamente desarrollada y no existía un importante desarrollo del comercio internacional y de las inversiones. $S$. TONDAPU, Gautami. (2010). International Institutions and Dispute Settlement :The Case of ICSID. EN: Bond Law Review. V. 22, I.1. Artículo 4. p. 13. Disponible en : http://epublications.bond. edu.au/blr/vol22/iss1/4/?utm_source=epublications.bond.edu. hacen parte de la Convención de Washington. Sudáfrica y Pakistán critican los tratados de inversiones. Estados Unidos y Canadá modifican los textos de negociación de sus tratados.

En el caso de Latinoamérica se vive un momento bastante peculiar. Varios países se encuentran en una cruzada contra el CIADI y la celebración de tratados de inversión, mientras que otros países, como Colombia, realizan todos sus esfuerzos por atraer la inversión a través de la negociación y conclusión de tratados. Se estima que en el año 2007 el 15\% de los casos concluidos ante el CIADI tenían que ver con demandas contra Estados latinoamericanos; para el año 2009 ya se hablaba de un 52\% ${ }^{60}$. El 22 de abril del 2013 se reunieron en Guayaquil representantes de Bolivia, Cuba, Ecuador, Nicaragua, República Dominicana, San Vicente y las Granadinas, Venezuela, Argentina, Guatemala, Honduras y México con el fin de discutir los impactos de los tratados bilaterales de inversión en la región y quitarle el contencioso al CIADI. Cecila Olivet, del Instituto Transnacional, en una columna en el Network for Justice in Global Investment ${ }^{61}$, afirma que la iniciativa de estos países responde al creciente número de demandas por parte de corporaciones internacionales contra gobiernos latinoamericanos ante tribunales internacionales, así como laudos recientes que contienen indemnizaciones multimillonarias como el caso de Ecuador contra OXY, en donde el gobierno ecuatoriano fue condenado a pagar una suma de US2.3 billones de dólares ${ }^{62}$. El

au\%2Fblr\%2Fvol22\%2Fiss1\%2F4\&utm_medium=PDF\&utm_ campaign=PDFCoverPages

60 VINCENTELLI, Ignacio. (2009). The Uncertain Future of ICSID in Latin America. Selected Works, p.11. Disponible en: http:// papers.ssrn.com/sol3/papers.cfm?abstract_id=1348016

61 OLIVET, Cecilia. (Abril de 2013). Report from Latin America and Caribbean governments meeting on investment regime, in Guayaquil, Ecuador. EN: Network for Justice in Global Investment. Instituto Transnacional. Disponible en: http:// justinvestment.org/2013/05/report-from-latin-america-andcaribbean-governments-meeting-on-investment-regime-inguayaquil-ecuador/

62 El 27 de mayo de 2013 el Presidente de Ecuador, Rafael Correa, calificó de ataque contra la soberanía del Estado los tratados bilaterales de inversión en donde el capital tiene más derechos que los seres humanos. Cuestionó el hecho de que las transnacionales pudieran perseguir a un Estado soberano sin acudir a las instancias jurídicas internas. Asimismo, criticó la condena contra Ecuador en el caso OXY ante el CIADI por una declaratoria de caducidad del Contrato de explotación de una zona petrolera en el Amazonas. El Presidente Correa indicó que el monto exigido ante el CIADI sobrepasa el presupuesto anual de salud del país latinoamericano. El Ciudadano. (27 de mayo de 2013). Le Président Correa critique les traités d'investissements réciproques pour porter atteinte aux Etats. EN: El Ciudadano. Disponible en: http://www.elciudadanogob.ec/index php? option $=$ com_content $\&$ view $=$ article $\&$ id $=42377$ :le-president - 
objetivo de la reunión era coordinar políticas de cooperación para asistencia recíproca en procesos de arbitraje internacional de inversiones. Stuart Trew, explica que ésta reacción de los países latinoamericanos tiene como origen, igualmente, los comportamientos de las compañías trasnacionales de minería canadienses. Por citar algunos ejemplos, Infinito Gold demandó a Costa Rica por US\$1 billón de dólares sobre la base de un tratado celebrado con Canadá. En marzo Rusuro Mining, una empresa rusa con sus oficinas principales en Canadá, demandó a Venezuela por US $\$ 3.03$ billones de dólares valiéndose de un tratado celebrado con Canadá. Otro ejemplo es el de Pacific Rim, que pide a El Salvador US\$315 millones de dólares como compensación por la oposición de la comunidad a un proyecto de construcción de una mina de oro $^{63}$.

Por otro lado, autoridades de Pakistán y Sudáfrica han manifestado su descontento con los riesgos de los tratados bilaterales de inversión. El caso de Pakistán es particular. En el año 2001 el gobierno pakistaní recibió una carta sobre una disputa con una empresa suiza, llamada Société Générale de Surveillance (SGS), por una terminación de un contrato en 1996 que había sido adjudicado, producto de supuestos sobornos. La carta provenía del CIADI indicando que SGS reclamaba más de US\$110 millones como compensación, sobre la base de violaciones a un tratado de inversión. Estos hechos llevaron a que se le preguntara a Makhdoom Ali Khan, Procurador General de Pakistán, lo que conocía sobre esta instancia y la posibilidad de reclamar pretensiones de este estilo. El Procurador en una entrevista concedida en el 2009 confesó que en ese momento, a pesar de ser experto en derecho internacional público, no conocía el tema. De hecho fue a través de google que conoció las implicaciones del CIADI y de los TBI. Se percató así del lenguaje extremadamente amplio de los tratados, la posibilidad para los inversionistas extranjeros de arreglar sus disputas por fuera del sistema legal interno y a través del arbitraje internacional de inversiones,

correa-critique-les-traites-dinvestissements-reciproques-pourporter-atteinte-aux-etats\&catid=68:francais\&Itemid=109

63 TREW, Stuart. (Mayo 8 de 2013). Latin American countries pushing back against investor 'rights' in trade deals. EN: Rabble. Disponible en: http://rabble.ca/blogs/bloggers/ council-canadians/2013/05/latin-american-countries-pushingback-against-investor-righ?goback=\%2 Egde_3948480_ member_240832431 y las opciones limitadas para apelar un laudo de estas características. Se percató así, de que en caso de que Pakistán no quisiera ejecutar el eventual laudo, la Convención de Washington permitiría a SGS buscar la ejecución de la decisión y pagarse con los bienes comerciales de Pakistán en cualquiera de los países signatarios de la Convención. En realidad, la firma de los tratados de la época se hacía casi mecánicamente cuando los delegados del gobierno pakistaní y delegados extranjeros se encontraban, con el fin de dar una buena imagen ante la prensa, o como muestra de buena $\mathrm{fe}^{64}$.

Sudáfrica comenzó a reevaluar sus políticas internacionales en materia de tratados tras una demanda de 2007 interpuesta por varios ciudadanos italianos y una empresa de Luxemburgo, bajo el tratado Bélgica-Luxemburgo. Los demandantes argumentaron que una ley de 2004, sobre el desarrollo de los recursos mineros y petroleros, adoptada con el objetivo de incrementar la participación de los ciudadanos sudafricanos - por mucho tiempo desfavorecidos - en la industria minera, representaba una expropiación de sus derechos de extracción. El caso sirvió de incentivo al gobierno para reconsiderar su política de inversiones, ya que “... los tratados bilaterales de inversión representaban un riesgo y limitaban la capacidad del gobierno de proseguir su programa de transformación de la Constitución"65. El gobierno manifestó, en el 2012, su intención de terminar el tratado bilateral de inversiones con la Unión Económica BelgoLuxemburguesa. De la misma manera anunció la no renovación de doce tratados de inversión celebrados con países de la Unión Europea. El 23 de junio de 2013 Sudáfrica envió una notificación a España denunciando el tratado bilateral de inversiones $^{66}$. Las razones principales yacen en las

64 SKOVGAARD POULSEN, Lauge N. (2011). Sacrificing Sovereignty by chance : Investment treaties, Developing Countries, and Bounded Rationality. EN: The London School of Economics and Political Science, p. 13-16. Disponible en: http:// etheses.lse.ac.uk/141/1/Poulsen_Sacrificing_sovereignty_by_ chance.pdf

65 Investment treaty news - Nouvelles en Bref. (2012). L'Afrique du Sud a pesé les risques et les bénéfices des TBI. EN: Un journal trimestriel sur le droit et la politique des investissements dans la perspective du développement durable. No. 1., V.3., p.13. Disponible en: http://www.iisd.org/pdf/2012/iisd_itn_ october_2012_fr.pdf

66 RUEDA, José Ángel. (30 de junio de 2013). South Africa denounces BIT with Spain. Africa International Legal Awareness. Disponible en: http://blogaila.com/2013/06/30/ south-africa-denounces-bit-with-spain-by-jose-angel- 
evidentes ventajas de los inversionistas frente al Estado y la falta de flexibilidad de los tratados en puntos críticos de política pública ${ }^{67}$.

Australia se convirtió, hace poco, en el primer país desarrollado en anunciar que no volvería a incluir cláusulas de arbitraje, inversionistaEstado, en sus tratados. El gobierno australiano anunció ésta decisión en abril del 2011 por dos argumentos principales: (i) los tratados parecen otorgar mayores derechos a los inversionistas extranjeros que a los locales; (ii) El arbitraje de inversiones pone en riesgo la posibilidad de Australia de decidir sobre sus propias políticas públicas. Los principales sectores de preocupación fueron los de la salud pública y el medio ambiente. Igualmente, se criticó la parcialidad a favor de los inversionistas por parte de los tribunales y la inconsistencia de las decisiones arbitrales, debido a la falta del sistema de precedente. Partidarios de las medidas del gobierno australiano sostienen que existen otras opciones como los seguros contra riesgos políticos o la conclusión de contratos específicos con el Estado en donde se quiere invertir; esta última opción se enfrentaría al problema de que solo los inversionistas con un fuerte poder económico podrían tener un peso de negociación frente a los Estados ${ }^{68}$.

India, por otro lado, ha anunciado que iniciará la revisión de 82 de sus tratados bilaterales de inversiones. Parte de la crisis surgió por el laudo de White Industries contra la India, en donde se reconocieron cerca de 10 millones de dólares australianos por concepto de daños por las demoras de las cortes locales en la ejecución de un laudo arbitral anterior, proferido en el año 2002 y que en el 2010 todavía no había podido ejecutarse. Empresas como Vodafone,

rueda/?goback=\%2Egde_3937212_member_254309662

67 LEON, Peter; VEERAN, Jonathan; \& WARMINGTON, Erin. (5 de octubre 2012). South Africa Declines To Renew Bilateral Investment Treaties With European Union Member States. Mondaq. Disponible en: http://www.mondaq.com/x/199586/ international+trade+investment/South + Africa + Declines + To + Renew+Bilateral+Investment+Treaties+With+European+Unio $n+$ Member+States Ver igualmente: WOLFREY, Sean. (Marzo 6 de 2003). South Africa's new investment policy framework and protection for SA firms investing abroad. Tralac-Trade Law Center. Disponible en: http://www.tralac.org/2013/03/06/ south-africas-new-investment-policy-framework-andprotection-for-sa-firms-investing-abroad/

68 MONICHINO, Albert \& FAWKE, Alex. (Mayo de 2013). Australia and the Backlash against Investment Arbitration. Barristers. Disponible en : http://barristers.com.au/news-resources/ recent-publications/
Sistema, Telenor y Children's Investment Fund han iniciado procedimientos arbitrales por cambios del gobierno en la regulación y la enmienda al Código tributario. A pesar de que India no hace parte de la Convención de Washington, se encuentra en un proceso de reevaluación de los términos de sus tratados para darle una mayor importancia al Estado y permitir, así, que éste pueda iniciar un procedimiento arbitral y no solo los inversionistas ${ }^{69}$.

Estados Unidos, Canadá y México ${ }^{70}$ concluyeron el Tratado de Libre Comercio de América del Norte también conocido como "TLCAN" creó una de las áreas de libre comercio más grandes del mundo, con un mercado aproximado de 450 millones de personas ${ }^{72}$. No obstante, la aplicación del Tratado no siempre fue pacífica. El Capítulo 11 del TLCAN, que trata el tema de inversiones, estuvo en el foco de fuertes debates dadas las interpretaciones flexibles que los tribunales arbitrales, constituidos en virtud del Tratado, daban sobre su aplicación y su alcance. Esto llevó a la Comisión de Libre Comercio a un replanteamiento sobre los alcances del Capítulo $11 \mathrm{y}$, en especial, a la interpretación del nivel mínimo de tratamiento conforme al derecho internacional ${ }^{73}$.

69 S. BHUSHAN PUNEETH Nagaraj. (Enero 6 de 2013). Need to align bilateral investment treaty regime with global reality. The Hindu. Disponible en : http://www.thehindu.com/business/ companies/need-to-align-bilateral-investment-treaty-regimewith-global-reality/article4276916.ece

70 México no hace parte de la Convención de Washington pero ha sido parte a diferentes arbitrajes TLCAN (Tratado de Libre Comercio de América del Norte).

71 Tratado de Libre Comercio de América del Norte entre el gobierno de Canadá, México y Estados Unidos. Diciembre 17, 1992.

72 Office of the United States Trade Representative. http:// www.ustr.gov/trade-agreements/free-trade-agreements/northamerican-free-trade-agreement-nafta

73 North American Free Trade Agreement. (2001). Notes of Interpretation of Certain Chapter 11 Provisions. NAFTA Free Trade Commission. En esta nota aclaratoria se afirmó que el artículo 1105(1) del Tratado establece: (i) "el nivel mínimo de trato a los extranjeros propio del derecho internacional consuetudinario, como el nivel mínimo de trato que debe otorgarse a las inversiones de los inversionistas de otra Parte. (ii) Los conceptos de "trato justo y equitativo" y "protección y seguridades plenas" no requieren un trato adicional al requerido por el nivel mínimo de trato a los extranjeros propio del derecho internacional consuetudinario, o que vaya más allá de éste. (iii) Una resolución en el sentido de que se haya violado otra disposición del TLCAN o de un acuerdo internacional distinto no establece que se haya violado el artículo 1105(1)". http://www. sice.oas.org/TPD/NAFTA/Commission/CH11understanding_s. asp 
Algunos estudios sugieren que los tratados suelen ser más favorables para los países exportadores que para los países prominentemente importadores. Gus Van Harten toma, como ejemplo, el tratado de inversión entre Estados Unidos y el Ecuador, en donde el primero excluyó del tratado las obligaciones preestablecidas en más de diez actividades, mientras que el segundo se limitó a excluir tan solo unas pocas ${ }^{74}$. Esto permitía a Estados Unidos mantener el control de sectores estratégicos de su economía y muestra tan solo un ejemplo de la desigualdad manifiesta en algunos tratados negociados por los Estados.

2.1.2 Críticas constantes a los tratados de inversión y al arbitraje internacional de inversiones

Se cuestiona la falta de igualdad entre las partes. Uno de los puntos cruciales gira en torno a que solo el inversionista puede poner en movimiento el procedimiento arbitral. El Estado no demanda al inversionista ante el CIADI. El Estado es el único responsable de pagar indemnizaciones por violaciones al tratado. Sin embargo, esta afirmación es necesario relativizarla, puesto que se han visto casos en los que el Estado demanda y pone en movimiento el arbitraje, por citar algunos ejemplos: Gabón contra la Société de Serete S.A. ${ }^{75}$; el Gobierno de la Provincia de East Kalimantan (Gobierno provincial en Indonesia) contra PT Kaltim Prima Coal y otros ${ }^{76}$; y el caso Tanseco (Compañía de electricidad de carácter estatal) contra $I P T L^{77}$.

Asimismo, el inversionista puede someter al tribunal arbitral litigios de carácter contractual. A pesar de que el arbitraje de inversiones se basa, fundamentalmente, en violaciones a los estándares de protección incluidos en los tratados, en algunos tratados los términos de la cláusula compromisoria son tan amplios que le dan directamente competencia al tribunal arbitral para conocer sobre diferendos surgidos del contrato. Por esta razón, en numerosas ocasiones, los tribunales de arbitramento se han

74 Tratado de inversiones entre Estados Unidos y Ecuador. Washington. 27 de agosto de 1993 y entró en vigor el 11 de mayo de 1997. Ver igualmente: Van Harten, Gus. Op. cit., p. 43-44.

75 Caso CIADI No. ARB/76/1. Gabón contra la Société de Serete S.A.

76 Caso CIADI No ARB/07/03. Gobierno de la Provincia de East contra PT Kaltim Prima Coaly otros.

77 S. BHUSHAN PUNEETH Nagaraj. Op. cit. pronunciado con relación a problemas netamente contractuales, lo cual implica grandes dificultades para los Estados durante la ejecución contractual y el uso de sus facultades excepcionales.

Existe otra figura que ha sido fuertemente criticada, es conocida como el forum shopping. Consiste en la posibilidad para el inversionista extranjero, que no es beneficiario del tratado, de adquirir la nacionalidad del Estado-parte del tratado por el simple hecho de establecer un grupo empresarial en el Estado del cual busca beneficiarse. Un ejemplo es el tratado entre Zimbabue y Holanda, al no existir un tratado de inversiones entre Zimbabue y Estados Unidos, un inversionista que desee invertir en Zimbabue puede estructurar su inversión a través de Holanda para poder acceder a los beneficios del tratado ${ }^{78}$. Esto se ha visto en algunos casos que involucraban a Venezuela, lo cual motivó la denuncia de la Convención de Washington, dejando en evidencia a Holanda como el país preferido por los inversionistas extranjeros en la práctica del forum shopping. El profesor Gus Van Harten, explica que a través de esta figura, una inversión que originalmente era doméstica, por el hecho de pertenecer a nacionales del Estado receptor de la inversión, puede volverse extranjera por un simple papel de transferencia de la propiedad a una persona o entidad extranjera ${ }^{79}$. El forum shopping ha causado estragos en los países en desarrollo y ya se han visto casos en Colombia $^{80}$. Sin embargo, la posibilidad de que ocurra esta práctica radica, en gran medida, en la manera en que se encuentre redactado el tratado. Un caso conocido es el de Tokios Tokelés contra Ucrania ${ }^{81}$, el cual permitió a un grupo de ucranianos demandar a su propio gobierno, bajo el tratado bilateral de inversiones entre Ucrania y Lituania, a través de una compañía que había sido constituida en Lituania. Un caso curioso de forum shopping es el del tratado bilateral de inversiones

78 VAN OS, Roos \& KNOTTNERUS, Roeline. (2011). A gateway to " treaty shopping " for investment protection by multinational companies. EN: SOMO (Ed.). Dutch Bilateral Investment Treaties. Ámsterdam.

79 VAN HARTEN, Gus. Op. cit., p. 28-29.

80 El ex-ministro de Agricultura José Antonio Ocampo criticó la práctica de algunos empresarios colombianos de crear empresas en el exterior para llegar al país como inversionistas de capital extranjero y acceder a protecciones más amplias que los inversionistas colombianos gracias a los tratados. (Proyectos UAF). El Tiempo. "Es aberrante fungir como inversionista extranjero". Martes 2 de julio de 2013, p. 12

81 Caso CIADI No ARB/02/18. Tokios Tokelés c/Ucrania. 
entre el Reino Unido y Egipto, el cual permite a los inversionistas ingleses acudir al forum shopping en los casos contra la República Árabe de Egipto, pero que no permite el mismo forum shopping a favor de los inversionistas egipcios ${ }^{82}$.

Otro ejemplo es el del norteamericano Ronald Lauder contra la República Checa. Lauder demandó a la República Checa a través del tratado celebrado entre los Estados Unidos y la República Checa, y después presentó una nueva demanda pero esta vez amparándose por el tratado celebrado entre la República Checa y Holanda, dado que la inversión había sido estructurada a través de una sociedad holandesa. La primera demanda no prosperó pero la República Checa fue condenada en el segundo arbitraje por un valor de US\$270 millones de dólares, más intereses, lo cual equivalía al presupuesto total de salud ${ }^{83}$.

Existe otra cláusula de los tratados que ha causado muchos problemas, es conocida como la cláusula de la Nación la más favorecida o most favoured nation clause (MFN). Esta permite al inversionista valerse del régimen de favor, instaurado en los tratados del Estado receptor de la inversión - que no corresponde al tratado suscrito entre éste y su Estado de origen -, en caso que exista un beneficio más grande otorgado a otros inversionistas extranjeros. La cláusula MFN se encontraría en el tratado entre el Estado de origen del inversionista y el Estado receptor, y reenviaría a los otros tratados suscritos por el Estado receptor. Esto puede representar un riesgo, no necesariamente previsto por el Estado. Un ejemplo es el caso Maffezini contra España ${ }^{84}$ : El tratado entre Argentina y España requería someter el diferendo al "tribunal competente" en España, si no se lograba llegar a un acuerdo amigable. En ausencia de disposición contraria, la disputa debía dirimirse por un tribunal de arbitramento, en caso de que las corte locales no pudieran poner fin a la disputa o si ninguna decisión de fondo era tomada en un periodo de

82 Acuerdo de Promoción y Protección de Inversiones entre el Reino Unido e Irlanda del Norte y Egipto. Londres, 11 de junio de 1975 que entró en vigor el 24 de febrero de 1976.

83 EBERHARDT, Pia \& OLIVET, Cecilia. Op. Cit., p.26.

84 Caso CIADI No ARB/97/7. Maffezini (Emilio Agustín) c/ España. Decisión de jurisdicción, 25 de enero de 2000. Ver igualmente: Caso CIADI No ARB/02/3. Aguas del Tunari c) Bolivia. Decisión de objeciones de jurisdicción 2005. Ver igualmente: Siemens A.G. c/ Argentina. CIADI Caso No. ARB/02/8. Decisión de jurisdicción. Agosto 3 de 2004. https:// icsid.worldbank.org/ICSID/FrontServlet
18 meses, a partir del inicio de los procedimientos locales. El demandante acudió a la justicia arbitral sin cumplir con estos requerimientos previos, sin embargo, argumentó ante el tribunal de arbitramento que el tratado entre España y Chile no contenía requisitos previos para acudir al arbitraje y que la cláusula MFN del tratado entre España y Argentina le permitía valerse de ese tratamiento de favor de los inversionistas chilenos, debiéndose declarar el tribunal competente para conocer del caso. A pesar de que el tribunal intentó imponer algunos limites a la utilización de la cláusula MFN, aceptó los argumentos del demandante y se declaró competente para conocer del fondo del litigio. En casos ulteriores se intentó poner más limites al uso de la cláusula MFN y se discutió su aplicabilidad respecto de la cláusula compromisoria $^{85}$, sin embargo, sigue siendo una de las provisiones más controvertidas de los tratados ante las instancias arbitrales, y de las que más merece atención por parte de los redactores y negociadores de los tratados, para evitar que los inversionistas se "salten" el requisito impuesto por algunos de estos instrumentos de agotar, primero, los recursos locales antes de acudir al arbitraje.

La independencia e imparcialidad de los árbitros también ha sido atacada. Es común que una misma persona sea árbitro, asesor y negociador de un tratado de inversión. Esto se debe a que el circulo de árbitros, en el arbitraje de inversiones, es muy pequeño y en numerosas ocasiones se puede encontrar árbitros que al mismo tiempo que cumplen su función, promueven la inclusión de cláusulas compromisorias en las relaciones entre Estados e inversionistas extranjeros ${ }^{86}$, o incluso son abogados defensores de inversionistas en otros casos de inversión. Esto plantea un problema de independencia e imparcialidad. Existen casos en los que un árbitro internacional de inversiones puede tener una participación importante en la

85 Ver igualmente: Caso CIADI No ARB(AF)/00/2. Técnicas Medioambientales Tecmed SA c/ México. Laudo de mayo 29 de 2003. Caso CIADI No ARB/01/7. MTD Equity Sdn Bhd y MTD Chile SA c/ República de Chile. Laudo de mayo 25 de 2004. Caso CIADI No ARB/02/8. Siemens AG c/ Argentina. Decisión de Agosto 3 de 2004. Caso CIADI No ARB/02/13. Salini Costruttori SpA y Italstrade SpA c/ Jordania. Decisión de noviembre 15 de 2004. Caso CIADI No ARB/03/24. Plasma Consortium Ltd c/ República de Bulgaria. Decisión de Febrero 8 de 2005. Caso CIADI No ARB/ 07/17. Impregilo S.p.A. c/ Argentina. Caso CIADI No. ARB/07/31. Hochtief Aktiengesellschaft c/ Argentina.

86 VAN HARTEN, Gus. Op. cit., p. 39-40. 
negociación de algunos de los tratados que más tarde se encargará de interpretar, como árbitro, o de defender/atacar, como abogado. Se puede argumentar que en realidad estas personas están en la mejor posición para entender las implicaciones en la negociación de los tratados y buscar una verdadera igualdad entre las partes a través de su experiencia. El inconveniente resulta cuando al hacer parte de las negociaciones, en futuros conflictos, se hace evidente que el lenguaje utilizado en los instrumentos es demasiado ambiguo, y esas mismas personas, esta vez como árbitros o abogados de las partes, interpretan el alcance de las disposiciones, el cual en una gran mayoría de los casos resulta a favor de los inversionistas. Recordemos que son los mismos inversionistas los únicos que pueden interponer una demanda de inversión, y constituir así un tribunal de arbitramento. El no satisfacer, en cierta medida, sus intereses, podría tener como consecuencia la renuncia del inversionista a acudir a este tipo de mecanismo.

Es necesario enfatizar que los árbitros, en el mundo del arbitraje internacional de inversiones, constituyen un grupo muy pequeño. De hecho, 15 árbitros han tomado las decisiones en un 55\% de los casos conocidos hasta el año 2012 en materia de tratados de inversión ${ }^{87}$. Esto no necesariamente le quita legitimidad a sus decisiones, sin embargo, despierta preocupaciones dejar en un grupo tan reducido de personas la toma de decisiones que tienen implicaciones tan grandes para los Estados.

Asimismo se cuestiona la neutralidad e imparcialidad del sistema dado la gran tendencia en el CIADI de fallar a favor del inversionista extranjero. A pesar de esto Ignacio Vincentelli señala que en la práctica, en un número significativo de casos, se han reducido los montos de compensación de los inversionistas de manera importante y muchos laudos CIADI han sido anulados. Un ejemplo sería el de Autopista Concesionaria de Venezuela contra Venezuela en donde se le reconoció al inversionista una compensación de 12 millones de dólares, cuando

87 EBERHARDT, Pia \& OLIVET, Cecilia. Op. cit., p.38-41. Los 15 árbitros nombrados en este estudio son: Brigittte Stern, Charles Brower, Francisco Orrego, Marc Lalonde, Yves Fortier, Gabrielle Kaufmann-Kohler, Albert Jan van den Berg, KarlHeinz Bockstiegel, Bernard Hanatiau, Jan Paulsson, Stephen M. Schwebel, Henri Alvarez, Emmanuel Gaillard, William W. Park, Daniel Price. en realidad las pretensiones se elevaban a 311 millones de dólares ${ }^{88}$.

El costo que implica un arbitraje de inversión es otro argumento en contra. Se calcula que el costo de un arbitraje Estado-Inversionista puede ascender a US\$8 millones de dólares y en algunos casos superar los US\$30 millones; más del $80 \%$ de los costos legales se gastan en concepto de representación y consejeros ${ }^{89}$. Los costos son asumidos por las partes y cubren la administración del arbitraje, la práctica de pruebas, los honorarios de los abogados y de los árbitros, entre otros. Filipinas, por ejemplo, invirtió más de US\$58 millones de dólares para defenderse en dos casos contra la empresa Fraport. Bulgaria pagó más de US\$13 millones de dólares por asesoría jurídica en el caso que la opuso a Plama Consortium y solo fue indemnizada por este concepto por US\$7 millones ${ }^{90}$. En el caso Pey Casado contra Chile ${ }^{91}$ los costos de justicia del demandante se elevaban a US\$11 millones de dólares y los del defensor a US $\$ 4,3$ millones; el defensor tuvo que pagar $75 \%$ de los costos del arbitraje más US $\$ 2$ millones de los costos del demandante ${ }^{92}$. En el caso ADC Affiliate Limited y $A D C \& A D M C$ Management Limited contra la República de Hungría ${ }^{93}$, el tribunal condenó a Hungría a pagar la totalidad de los costos del arbitraje por un valor de US\$7,6 millones de dólares $^{94}$. En el caso Waguih Elie George Siag y Clorinda Vecchi contra la República árabe de Egipto $^{95}$ el tribunal juzgó que los demandantes estaban habilitados a recibir una suma de US\$6 millones de dólares a título de costos de justicia, de experticia y de otros gastos ${ }^{96}$.

88 VINCENTELLI, Ignacio. (2009). Op. cit., p.14. 89 EBERHARDT, Pia \& OLIVET, Cecilia. Op. cit., p. 7-8, 15.

90 Caso CIADI No ARB/03/24. Plasma Consortium Ltd c/ República de Bulgaria. Decisión de Febrero 8 de 2005.

91 Caso CIADI No ARB/98/2. Víctor Pey Casado y President Allende Foundation c/Chile.

92 Dispute Settlement. International Center for Settlement of Investment Disputes. Op. cit., p. 19.

93 Caso CIADI No ARB/03/16. ADC Affiliate Limited y ADC \& ADMC Management Limited c/ República de Hungría.

94 Dispute Settlement. International Center for Settlement of Investment Disputes. Op. cit., p. 19.

95 Caso CIADI No ARB/05/15. Waguih Elie George Siag y Clorinda Vecchi c/ República Árabe de Egipto.

96 Dispute Settlement. International Center for Settlement of Investment Disputes. Op; cit., p. 20. 
El arbitraje de inversiones puede ser un buen negocio, se ha llegado a afirmar que llevar una demanda de US $\$ 1.000$ millones o ganar 100 millones de dólares ya no tiene gran significado para una firma de abogados de arbitraje de inversiones "lo que se necesita estos días para despuntar es una indemnización de 350 millones de dólares como mínimo"197. Los honorarios de los árbitros oscilan entre US\$375 y US\$700 dólares la hora. Por una controversia de US $\$ 100$ millones de dólares, un árbitro puede ganar hasta US\$350.000 dólares ${ }^{98}$.

Los costos del arbitraje de inversiones no han impedido que los inversionistas que no cuentan con los recursos para presentar una demanda de esta clase, encuentren financiación con el fin de obtener una jugosa condena en contra de los Estados. El arbitraje de inversiones se enfrenta hoy a la "financiación de terceros". Esta consiste en que un tercero decide invertir en el litigio existente entre el Estado y el inversionista con el fin de obtener un beneficio económico, en caso de que el Estado resulte condenado. El financiador recupera, por lo general, entre un $20 \%$ o un $50 \%$ del laudo final ${ }^{99}$. Esta forma de financiación despierta preocupaciones ya que "los terceros financiadores controlan el acceso a un circuito de arbitraje muy hermético. Tienden a aceptar casos cuyos consejeros son firmas de abogados líderes $y$, en caso de no estar contentos con la elección, sugerirán alternativas. También pueden influir en quién es designado como árbitro"100.

Estas críticas al sistema son solo un ejemplo de los cuestionamientos al arbitraje de inversión. Sin embargo, el sistema tiene sus ventajas, que pueden ser aprovechadas atendiendo a los

97 EBERHARDT, Pia \& OLIVET, Cecilia. (2012). Capitulo II Controversias relacionadas con tratados de inversión, Un gran negocio para la industria del arbitraje. EN: Helen Burley (Ed.). Cuando la injusticia es negocio. Cómo las firmas de abogados, árbitros y financiadores alimentan el auge del arbitraje de inversiones. Bruselas-Ámsterdam, p.14.

98 Ibid., Capitulo IV, ¿Quién vigila a los guardianes? Los conflictos de interés de los árbitros de inversiones, p.35.

99 Ibid., Capitulo V, Especulando con la injusticia. Financiación de controversias relativas a inversiones por parte de terceros, p.57.

100 Ibid., Capitulo V, Especulando con la injusticia. Financiación de controversias relativas a inversiones por parte de terceros, p.59. El informe señala como algunos de los financiadores conocidos a la empresa Burford Capital (US), Jurídica Investment LTD (Reino Unido), Omni Bridgeway (Países Bajos), Fullbrook Management (US) y Calunius Capital (Reino Unido). términos pactados por las partes en los tratados de inversión.

\subsection{Claves para la viabilidad del sistema}

La confianza depositada en el arbitraje de inversiones puede afianzarse gracias a una conducta responsable por parte de los Estados durante la negociación de los tratados, para evitar las interpretaciones amplías de los estándares de protección acordados a los inversionistas. Esto, sumado a una correcta política de cooperación interna entre las entidades estatales en la aplicación de los compromisos internacionales, lo cual podría evitar en muchos casos el contencioso internacional.

2.2.1 Diligencia en la negociación, restricción en la interpretación y prácticas de prevención

El arbitraje de inversiones necesita replantearse para prestar mayores garantías a sus dos principales usuarios: El Estado y el inversionista. No se trata de erradicarlo como método de resolución de conflictos internacional ni de abocar por una eliminación del CIADI como Centro principal de organización de este tipo de controversias, bajo los auspicios de la Convención de Washington. Sin embargo, existen muchos desafíos para reequilibrar la balanza entre los distintos intervinientes, fortaleciendo la confianza de los Estados en la participación en estos procesos. Casos como los de Argentina, Bolivia, Ecuador y Venezuela muestran una tendencia de algunos países en Latinoamérica por regresar a la doctrina Calvo, buscando cierta independencia de los Estados Unidos y un fortalecimiento de la soberanía en la región ${ }^{101}$. Sin embargo, este movimiento de rechazo al CIADI y de denuncia de la Convención también es contraproducente para la inversión, dada la perdida de seguridad jurídica de los inversionistas, lo cual puede tener como consecuencia que busquen otros mercados más atractivos, como el asiático o el africano. El caso de Colombia es diferente, ya que estamos ante un movimiento que favorece a los tratados y al CIADI.

El periodo de negociación de los tratados es de suma importancia y no debemos apresurarnos

101 FACH GOMEZ, Katia. (2010). Latin America and ICSID : David versus Goliath? Universidad de Zaragoza. Disponible en: http://papers.ssrn.com/sol3/papers.cfm?abstract_id=1708325 
en su celebración si con eso se están sacrificando intereses superiores. Los alcances del término inversión deben ser cuidadosamente escogidos y, más allá de determinar qué se debe entender por este concepto, se debe definir qué no se entiende comprendido en él. El contenido de inversión será determinante para la competencia del tribunal arbitral. Asimismo, los estándares mínimos de protección de la inversión deben ser estrictamente delimitados, el gobierno tiene que estar seguro de que se excluyan figuras como la del forum shopping y de que los términos de los tratados no sean incompatibles con reformas sociales y políticas en materia ambiental y de orden público -en la medida de lo posible-, con el fin de que el Estado no vea su responsabilidad comprometida por cambios legislativos ulteriores, que resulten necesarios para el desarrollo de los principios constitucionales internos.

Es necesario negociar las disposiciones prioritarias y determinar qué acuerdo prevalece en caso de conflicto; ser consciente de que un consentimiento amplio al arbitraje, como por ejemplo cláusulas de este tipo: "todos los diferendos que conciernen la inversión" o las cláusulas "sombrilla" como "todo compromiso acordado a título de la inversión", podrían comprometer al Estado en ámbitos que no había inicialmente planeado ${ }^{102}$.

Se debe igualmente formar abogados en el arbitraje internacional de inversiones. En el ámbito internacional, los despachos más importantes cuentan con muchos años de experiencia y se conocen entre si, por eso no es raro que los inversionistas sigan acudiendo a los mismos operadores jurídicos. No se puede pretender que formemos a profesionales cuando el contencioso ya haya explotado en Colombia, tampoco debe el gobierno esperar contratar siempre a consultores internacionales que con toda seguridad significarán un costo importante para las arcas del Estado. La asesoría externa es sana, aunque en Colombia existen muchos abogados de calidad que podrían formarse y

102 PAUWELYN, Joost. (Octubre de 2012). Faire face à la complexité croissante des traités d'investissement: Cadres et Conseils politiques. EN: Investment treaty news. Un journal trimestriel sur le droit et la politique des investissements dans la perspective du développement durable. No. 1., V.3., p.5-6. Disponible en: http://www.iisd.org/pdf/2012/iisd_itn_ october_2012_fr.pdf prepararse para afrontar esta nueva era que se avecina.

Por otro lado, el Estado no puede pretender adelantar cambios tan sustanciales si no existe una verdadera campaña interna de educación a las entidades estatales y los operadores jurídicos, sobre las consecuencias de los nuevos compromisos y la estrategia de prevención y confrontación de futuras demandas contra el Estado. La creación en Colombia de la Agencia Nacional de Defensa Jurídica del Estado es tan solo un paso más, que hay que aplaudir, para no vernos sorprendidos en el futuro mediato del arbitraje de inversiones, sin embargo, esto no es suficiente si en las entidades estatales todavía no saben de qué se trata este arbitraje.

El arbitraje internacional de inversiones debe evolucionar, debe resucitar aun más fuerte en el ámbito internacional, so pena de que los Estados encuentren otra manera de dirimir los litigios. Existen prácticas para la prevención de diferendos que deben ser adoptadas de manera sistemática. Las reglas de juego a nivel interno deben ser claras, si el inversionista tiene seguridad de que existe una entidad a la que puede dirigirse, con interlocutores calificados para discutir las diferencias antes de llegar al arbitraje, se podrá evitar futuras condenas o procedimiento innecesarios. Este nuevo periodo de aprendizaje del Estado, con sus entidades, debe pasar por una comunicación más estrecha entre los distintos órganos para evitar que una Entidad tome medidas susceptibles de violar compromisos internacionales, perjudicando a un inversionista extranjero. En algunos países, por ejemplo, se incentiva desde el comienzo de cualquier negociación con el inversionista a que un representante de la oficina del Procurador General esté presente ${ }^{103}$. En Colombia se ha comenzado a dar un buen ejemplo a nivel internacional para la coordinación de los distintos entes estatales para que un solo ente nacional reúna y establezca las pruebas pertinentes y que interesen al Estado. Este ente se encargará de recibir las notificaciones de diferendos, coordinar las consultas respectivas y representar al Estado en el eventual procedimiento arbitral ${ }^{104}$.

103 Dispute Settlement. International Center for Settlement of Investment Disputes. Op; cit., p. 72 y ss.

104 Ibid., p. 84-90. 
También resulta importante identificar cuáles son los sectores sensibles que podrían verse afectados por la conclusión de tratados. En efecto, existen algunos tipos de contratos en cada país que revisten una particular importancia y que se encuentran en el centro de la mayoría de diferendos de los inversionistas extranjeros (contratos de concesión, de obra pública, explotación de hidrocarburos, etc.). Cuando el Estado identifica de manera clara estos sectores sensibles, puede proceder a la aplicación de medidas preventivas para evitar violaciones a los compromisos internacionales ${ }^{105}$.

Existen otras prácticas recomendables que en ciertos eventos han sido acogidas en los tratados celebrados por Colombia y que tiene que ver con el agotamiento de otros recursos a nivel interno antes de acudir al arbitraje, como por ejemplo el tratado entre Colombia y la Unión Económica Belgo-Luxemburguesa ${ }^{106}$. Esto permite proteger algunos sectores de especial relevancia para el gobierno, imponiendo el requisito de acudir primero a las cortes locales.

De igual manera, deben existir funcionarios con los poderes suficientes para llevar negociaciones con los inversionistas y otorgarles autorizaciones presupuestales que les permitan hacer uso del dinero público. Estas autorizaciones suelen existir cuando entidades son condenadas por tribunales nacionales, aunque no necesariamente por compensaciones a raíz de un procedimiento arbitral internacional. Uno de los inconvenientes para las entidades es saber quién deberá pagar la suma en caso de indemnización al inversionista, si la entidad involucrada en la violación, el organismo encargado de la negociación o el organismo responsable de la defensa del Estado ${ }^{107}$.

Otra medida adecuada para prevenir los conflictos es la existencia de un mediador independiente e imparcial o una oficina encargada de funciones de mediación designada por el gobierno o por el poder legislativo y que ejerza funciones de vigilancia; un interlocutor institucional que se pueda encargar de los

105 Ibid., p. 80-82.

106Tratado entre Colombia y la Unión Económica BelgoLuxemburguesa. Artículo XII. http://www.cancilleria.gov.co/ footer/juridicainternacional/tratados/inversion/suscritos 107 Dispute Settlement. International Center for Settlement of Investment Disputes. Op. cit., p. 90-92. conflictos que apenas están surgiendo, lo cual puede materializarse en un ahorro de tiempo y dinero antes de que el problema se agrave. Un buen ejemplo de esta figura se encuentra en la República de Corea en donde existe una organización sin ánimo de lucro que tiene como objetivo ayudar a los inversionistas y mejorar el ambiente de inversión en el país. Entre el año 2000 y el 2007 el KOTRA recibió más de 3.200 reclamaciones en distintos sectores industriales. En el 2007, 298 reclamaciones fueron resueltas por expertos locales, lo cual constituyó un 80,5 porciento de las reclamaciones presentadas ese año ${ }^{108}$.

Las soluciones negociadas pueden darse aun después de que la demanda arbitral haya sido interpuesta. A pesar de que no existen cifras exactas sobre el número de casos que han terminado por transacción dado el carácter confidencial de la mayoría de negocios, se estima que al año 2008, se abandonó el procedimiento en 48 casos al haberse llegado a una solución negociada. Se estima que un $30 \%$ de los casos registrados ante el CIADI hasta el año 2005 fueron solucionados gracias a la negociaciones entre las partes ${ }^{109}$. Un ejemplo es el caso CIADI entre Western NIS Enterprise Fund y Ucrania en el 2006, el cual fue abandonado después de que las Partes llegaran a un acuerdo ${ }^{110}$.

\subsubsection{Consecuencias de la figura en Colombia}

Las implicaciones de esta nueva clase de arbitraje pueden ser enormes para el país. En el año 2006, las pretensiones de los 30 casos pendientes ante el CIADI que involucraban a la República de Argentina, por las medidas tomadas durante la crisis económica de 2001, se estimaban en una suma de US $\$ 17$ billones, lo cual equivalía al presupuesto entero anual del gobierno sudamericano ${ }^{111}$. A finales del 2008, Argentina debía US $\$ 1.150$ millones de dólares por laudos proferidos en su contra ${ }^{112}$. Esto sin olvidar el caso comentado en este escrito

108 Dispute Settlement. International Center for Settlement of Investment Disputes. Op. cit., p. 94-100.

109 Dispute Settlement. International Center for Settlement of Investment Op. cit., 104-105.

110 Caso CIADI No ARB/04/2. Western NIS Enterprise Fund c/ Ucrania.

111 Ibid., p. 15.

112 EBERHARDT, Pia \& OLIVET, Cecilia. Op. cit., p.19. 
sobre la República Checa, que fue condenada por un monto equivalente al presupuesto total de salud del gobierno y el doble del déficit del sector público del año $2003^{113}$.

A esto se suma otro acontecimiento, muchas firmas internacionales de abogados incentivan a empresas multinacionales a presentar demandas cuando se percatan de cambios políticos, económicos o sociales susceptibles de perjudicar a sus clientes. Por ejemplo, en el 2011 después de las revoluciones de la llamada "primavera árabe", en Libia se puso de manifiesto las condiciones favorables para activar algunos tratados celebrados por este país dado que no habían podido salvaguardar la seguridad física y la protección de instalaciones y de personal de las multinacionales. Otro ejemplo ocurrió en el 2012, cuando India autorizó la venta de un medicamento genérico, más barato que otro medicamento que estaba patentado, lo cual llevó a una firma de abogados a sugerir a los dueños de los medicamentos patentados que existía un escenario propicio para la presentación de demandas, en virtud de los tratados concluidos por India. De manera general, los cambios de regulación realizados por los Estados en materia social y de derechos humanos ${ }^{114}$, de medio ambiente ${ }^{115}$, salud pública, seguridad social o creación de nuevos impuestos, han sido considerados como eventos constitutivos de eventuales demandas por violación a los tratados de inversión; en ocasiones, las demandas de inversión son utilizadas solo como medio para presionar a los gobiernos para que cambien sus políticas públicas ${ }^{116}$.

El arbitraje de inversiones debe evolucionar y reequilibrar la balanza. Sin embargo, esto no se logrará a través de una reforma del CIADI, poco probable, ya que todos los Estados miembros deben tomar la decisión unánimemente. El CIADI maneja reglas que conciernen al procedimiento

113 SKOVGAARD POULSEN, Lauge N. Op. Cit., p. 15.

114 Caso CIADI No ARB/10/25. Border Timbers Limited, Border Timbers International (Private) Limited, y Hangani Development Co. (Private) Limited c/ República de Zimbabue. Igualmente: Caso CIADI No ARB/10/15. Bernhard von Pezold y otros c/ República de Zimbabue.

115 Caso CIADI No ARB/12/12. Vattenfall y otros c/ Alemania. (Pendiente). Igualmente : Caso CIADI No ARB/09/6. Vattenfall $A B$, Vattenfall Europe $A G$, Vattenfall Europe Generation $A G \mathrm{c} /$ Alemania. Laudo marzo 11 de 2011.

116 EBERHARDT, Pia \& OLIVET, Cecilia. Op. Cit., p.24-25-26. arbitral, pero no puede crear leyes sobre las cuales los tribunales deban basar sus decisiones. El verdadero cambio radica en los términos de los tratados de inversión ${ }^{117}$ y la buena práctica del arbitraje de inversiones a nivel interno.

La posición de algunos países latinoamericanos de crear una nueva instancia internacional de inversiones, que compita con el CIADI, es problemática, pero debe sopesar la necesidad de un sistema más justo que logre mejorar, al mismo, tiempo los niveles de desarrollo impulsando el crecimiento de la empresa extranjera en el territorio ${ }^{118}$. El Mercado Común del Sur (MERCOSUR) y la Comunidad Andina no han logrado imponerse y un nuevo organismo requeriría posicionarse como una mejor opción a la planteada por el CIADI. Las dificultades de implementar tal mecanismo serían grandes y demoradas ya que implicaría para los Estadosparte renunciar al CIADI, denunciar la Convención y comenzar un nuevo periodo de negociaciones en donde se incluyera en los tratados una nueva institución arbitral.

Para Colombia esto no parece ser una opción debido a que en este momento hacemos parte de ese bloque que quiere celebrar tratados de libre comercio y de inversión y que acepta al CIADI como Centro de resolución de conflictos. ¿Condena o indulto al arbitraje internacional de inversiones? $\mathrm{Ni}$ la una ni la otra. ¿Hay que abandonar el sistema CIADI? No. ¿Se requieren cambios bajo el sistema CIADI? Si. ¿Se puede contemplar otros escenarios de arbitraje de inversiones por fuera del CIADI? $\mathrm{Si}$, aunque también se puede aprovechar su experiencia. El arbitraje de inversiones puede brindarle más legitimidad al sistema estatal, lo importante yace en darse cuenta de que la autonomía privada y los intereses económicos no deben siempre prevalecer sobre los intereses públicos, es necesario conciliar las ventajas de la flexibilidad y la confidencialidad del arbitraje de inversiones, con las exigencias de legitimidad de las decisiones que tocan el interés público ${ }^{119}$.

117 WICK, Diana Marie. (2012). The Counter-Productivity of ICSID Denunciation and Proposals for Change. EN: The Journal of International Business \& Law, p.288-289. Disponible en: http:// law.hofstra.edu/pdf/academics/journals/jibl/jibl_volxii_icsid_ wick.pdf

118 FACH GOMEZ, Katia. Op. cit., p.47-48.

119 BESSON, Samantha. (2005). La légitimité de l'arbitrage d'investissement. Jusletter, $p$. 15-16. Disponible en: http:// doc.rero.ch/record/28136/files/La_l_gitimit_de_l_arbitrage 
Se requiere ayudar a los países receptores de la inversión a desarrollar y mejorar su sistema judicial y político para encontrarse en igualdad de condiciones con las potencias mundiales, la posibilidad de una instancia internacional de cooperación no debería descartarse ${ }^{120}$. Los países también deben ayudarse a ellos mismos, las demandas contra Colombia llegarán y seguramente el Estado será condenado a pagar compensaciones importantes en algunos casos, no por esto el arbitraje internacional de inversión perderá su legitimidad, pero por lo menos tenemos que buscar que las decisiones sean en lo posible predecibles, con el fin de que el sistema goce de credibilidad y de que los inversionistas y el Estado tengan absoluta claridad sobre las reglas de juego.

\section{CONCLUSIÓN}

La Convención de Washington y el CIADI conservan grandes ventajas y una de ellas, no despreciable, es la facilidad de la ejecución del laudo arbitral. Sin embargo, la ejecución de laudos CIADI se enfrentará a diversas problemáticas a nivel interno, como la posibilidad de que los tribunales arbitrales de inversión conozcan de las decisiones tomadas por entidades estatales sobre el fundamento de las potestades excepcionales, gracias a los términos de los tratados, o la gran incertidumbre del arbitraje en Colombia por las decisiones de la Corte Constitucional, que aun en momentos en los cuales existe un recurso de anulación ante el Consejo de Estado ha decidido pronunciarse, apoyándose de la acción de tutela, respecto de laudos que involucran a entidades estatales; a pesar de la prohibición de realizar revisiones sobre el fondo del laudo y el gran golpe que resulta para el arbitraje nacional o internacional permitir que la acción de tutela tumbe laudos, existiendo recursos legales para atacarlos ${ }^{121}$

Los retos del sistema de arbitraje de inversiones y en particular del sistema CIADI son cada vez más numerosos y antes de buscar un reemplazo, a favor de otras instituciones, debemos aprender a jugar con la que tiene más experiencia. Los problemas que se plantean no radican solo en los términos de la Convención de Washington o en las decisiones de los tribunales internacionales de arbitraje, el problema radica igualmente en los términos negociados en los tratados, el desconocimiento de este arbitraje en el país, la cooperación interna de las instituciones para enfrentarlo y la inseguridad jurídica interna alrededor de la ejecución del laudo y las reglas de arbitrabilidad. Si Colombia aceptó y decidió entrar en este nuevo campo de guerra, debe preparar todas sus armas para no verse sorprendida, como lo muestra la experiencia de otros países del mundo.

121 Corte Constitucional. Sentencia T-058 de 2009. Febrero 2 de 2009. Ver igualmente: Corte Constitucional. Sentencia T-225 de marzo 23 de 2010. Finalmente: Corte Constitucional. Sentencia T-288 de 2013. Mayo 20 de 2013. international_d_investissement.pdf p. 15-16.

120 Ibid., p. 17 y ss. La autora propone como medidas de asistencia internacional la creación de tribunales internacionales de inversión según las materias y las regiones implicadas lo cual para la autora podría ser más apto que un tribunal CIADI o TLCAN. Plantea igualmente el establecimiento de un Consejo democrático internacional para ayudar a remediar las debilidades de las instituciones judiciales y políticas nacionales, un Fondo Democrático Internacional de Garantía de las Inversiones como fondo suplementario e independiente de las garantías contractuales y financieras propuestas por las Partes al Acuerdo de Inversión y finalmente un Dividendo de Recursos Global para que una parte de los beneficios de un contrato de inversiones pueda ser reinvertido en el interés de los más pobres. 


\section{BIBLIOGRAFÍA}

- Audit, Bernard. (2010). Reconnaissance et exécution des sentences arbitrales hors CIRDI. En L.G.D.J. (Ed.), La Procédure Arbitrale Relative aux Investissements Internationaux. Bélgica.

- Blackaby, Nigel. (2005). El Contrato de Arbitraje. En Legis (Ed.), El arbitraje según los tratados de inversión y los capítulos de inversión en los tratados de libre comercio. Colombia.

- Bernardini, Piero. (2009). Liber Amicorum Bernardo Cremades. ICSID Versus NONICSID Investment Treaty Arbitration. En M.A. Fernández-Ballesteros y D. Arias, La Ley (Ed.).

- Besson, Samantha. (2005). La légitimité de l'arbitrage d'investissement. Jusletter. Disponible en: http://doc.rero.ch/ record/28136/files/La l gitimit de l arbitrage_international_d_investissement. pdf

- Burgos-De la Ossa, María Angélica \& LozadaPimiento, Nicolás. (2009). La protección diplomática en el marco de las controversias internacionales de inversión. Revista Colombiana de Derecho Internacional,15.

- CNUCED. Conférence des Nations Unies sur le Commerce et le Développement. (2010). Différends entre investisseurs et État : Prévention et modes de règlement autres que l'arbitrage. New York y Ginebra.

- Eberhardt, Pia \& Olivet, Cecilia. (2012). Cuando la injusticia es negocio. Cómo las firmas de abogados, árbitros y financiadores alimentan el auge del arbitraje de inversiones. En Helen Burley (Ed.). Bruselas-Ámsterdam.

- Fach Gomez, Katia. (2010). Latin America and ICSID : David versus Goliath ?. Universidad de Zaragoza. Disponible en: http://papers.ssrn. com/sol3/papers.cfm?abstract id=1708325

- Guzman, Andrew T. (1997-1998). Why LDC's Sign Treaties That Hurt Them : Explaining The Popularity of Bilateral Investment Treaties. Berkeley Law. 38 VA J. Int'l L. 639.
- Hallward-Driemeier, Mary. (2003). Do Bilateral Investment Treaties Attract FDI? Only a bit...and they could bite. World Bank, DECRG.

- History of the ICSID Convention. (1964). Informe del Presidente Broches del 9/7/1964. Vol. IV.

- Neumayer, Eric \& Spess, Laura. (2005). Do Bilateral Investment Treaties Increase Foreign Direct Investment to Developing Countries?. London School of Economics and Political Science, UK.

- Nziramasanga, Mudziviri, S. Inaba, Frederick \& Shreay, Sanatan. (2011). Do Bilateral Investment Treaties Deliver the Goods? Evidence from Developing Countries. Review of Applied Economics. Vol. 7, No. 1-2.

- North American Free Trade Agreement. (2001). Notes of Interpretation of Certain Chapter 11 Provisions. NAFTA Free Trade Commission.

- Orjuela, Carlos García. Senador de la República de Colombia. Ponencia presentada al Congreso durante los debates sobre el tratado de libre comercio. (2005). Competencias del Congreso de la República en Materia de Tratados Internacionales Procedimiento y Características de la Aprobación de Tratados Internacionales en el Ordenamiento Jurídico Colombiano.

- Reed, Lucy; Paulsson, Jan; y Blackaby, Nigel. (2004). Guide to ICSID Arbitration. London. En Kluwer Law International.

- S. Tondapu, Gautami. (2010). International Institutions and Dispute Settlement :The Case of ICSID. Bond Law Review. V. 22, I.1. Artículo 4.

- Skovgaard Poulsen, Lauge N. (2011). Sacrificing Sovereignty by chance : Investment treaties, Developing Countries, and Bounded Rationality. The London School of Economics and Political Science. Disponible en: http://etheses. 
lse.ac.uk/141/1/Poulsen Sacrificing sovereignty by chance.pdf

- Linetsky, Andrés Jana \& Klein Kranenberg, Johanna. (2008). La convención de Nueva York y el CIADI Reconocimiento y Ejecución de Laudos Arbitrales bajo la Convención de Washington. En Abeledo Perrot (Ed.). El Arbitraje Comercial Internacional, Estudio de la Convención de Nueva York con motivo de su $50^{\circ}$ aniversario. Tawil, Guido Santiago \& Zuleta, Eduardo. Buenos Aires.

- Tobin, Jennifer \& Rose-Ackerman, Susan. (2003 y 2005). Foreign Direct Investment and the Business Environment in Developing Countries: the Impact of Bilateral Investment Treaties. The William Davidson Institute at the University of Michigan Business School. Working Paper Number 587.

- Tobin, Jennifer \& Rose-Ackerman, Susan. (2006). Bilateral Investment Treaties: Do They Stimulate Foreign Direct Investment? Yale University. Disponible en: http:// s3.amazonaws.com/zanran storage/www. upf.edu/ContentPages/822485.pdf

- Dispute Settlement. International Center for Settlement of Investment Disputes. New York y Ginebra. (2003). United Nations Conference on Trade and Development.

- US. Embassy - Bogotá Colombia. (2011). An Overview of Arbitration in Colombia for U.S. Companies. Council of American Enterprises Colombian American Chamber of Commerce. Disponible en: http://export.gov/colombia/ static/Report\%20-\%20Arbitration \%20 in\%20Colombia\%20-\%20final\%206-1-11 Latest eg co 033097.pdf

- Van Harten, Gus. (2010). Five Justifications for InvestmentTreaties: ACritical Discussion. Trade, Law and Development. Vol. 2, No 1.

- Van Os, Roos \& Knottnerus, Roeline. (2011). A gateway to « treaty shopping » for investment protection by multinational companies. En SOMO (Ed.). Dutch Bilateral Investment Treaties. Ámsterdam.
- Villegas Carrasquilla, Lorenzo. (2011). Debates en torno al consentimiento al acuerdo arbitral por el Estado en el arbitraje internacional de inversiones. En Grupo Editorial Ibáñez (Ed.). Tratado de Derecho Arbitral. Bogotá, 2011.

- Vincentelli, Ignacio. (2009). The Uncertain Future of ICSID in Latin America. Selected Works. Disponible en: http://papers.ssrn. com/sol3/papers.cfm?abstract id=1348016

- Wick, Diana Marie. (2012). The CounterProductivity of ICSID Denunciation and Proposals for Change. The Journal of International Business \& Law. Disponible en: http://law.hofstra.edu/pdf/academics/ journals/jibl/jibl volxii icsid wick.pdf

- Artículos de Prensa

- El Tiempo. "Es aberrante fungir como inversionista extranjero". Martes 2 de julio de 2013, p. 12.

- El Ciudadano. (27 de mayo de 2013). Le Président Correa critique les traités d'investissements réciproques pour porter atteinte aux États. El Ciudadano. Disponible en: http://www.elciudadano. gob.ec/index.php?option =com content\&view $=$ article $\& i d=42377: 1 e-$ president-correa-critique-les-traitesdinvestissements-reciproques-pourporter-atteinte-aux-etats\&catid=68:francais\&Itemid=109

- Investment treaty news - Nouvelles en Bref. (2012). L'Afrique du Sud a pesé les risques et les bénéfices des TBI. Un journal trimestriel sur le droit et la politique des investissements danslaperspectivedu développementdurable. No. 1., V.3. Disponible en: http://www.iisd. org/pdf/2012/iisd itn october 2012 fr.pdf

- Leon, Peter; Veeran, Jonathan; \& Warmington, Erin. (5 de octubre 2012). South Africa Declines To Renew Bilateral Investment Treaties With European Union Member States. Mondaq. Disponible en: http://www.mondaq.com/x/199586/ international+trade+investment/ 
outh+Africa + Declines + To + Renew + Bilateral+Investment+Treaties +With+European+Union+Member+States

- Monichino, Albert \& Fawke, Alex. (Mayo de 2013). Australia and the Backlash against Investment Arbitration. Barristers. Disponible en : http://barristers.com.au/ news-resources/recent-publications/

- Olivet, Cecilia. (Abril de 2013). Report from Latin America and Caribbean governments meeting on investment regime, in Guayaquil, Ecuador. Network for Justice in Global Investment. Instituto Transnacional. Disponible en: http://justinvestment. org/2013/05/report-from-latin-americaand-caribbean-governments-meeting-oninvestment-regime-in-guayaquil-ecuador/

- Pauwelyn, Joost. (Octubre de 2012). Faire face à la complexité croissante des traités d'investissement: Cadres et Conseils politiques. Investment treaty news. Un journal trimestriel sur le droit et la politique des investissements dans la perspective du développement durable. No. 1., V.3. Disponible en: $\quad$ http://www.iisd.org/pdf/2012/ iisd itn october 2012 fr.pdf

- Rueda, José Ángel. (30 de junio de 2013). South Africa denounces BIT with Spain. Africa International Legal Awareness. Disponible en: http://blogaila.com/2013/06/30/southafrica-denounces-bit-with-spain-by-joseangel-ueda/?goback=\%2Egde 3937212 member 254309662

- S. Bhushan Puneeth Nagaraj. (Enero 6 de 2013). Need to align bilateral investment treaty regime with global reality. The Hindu. Disponible en : http://www.thehindu.com/ business/companies/need-to-align-bilateral-investment-treaty-regime-with-globalreality/article4276916.ece
- Trew, Stuart. (Mayo 8 de 2013). Latin American countries pushing back against investor 'rights' in trade deals. Rabble. Disponible en: http://rabble.ca/blogs/ bloggers/council-canadians/2013/05/ latin-american-countries pushing-back-against-investorigh? goback=\%2 Egde 3948480 member 240832431

- Wolfrey, Sean. (Marzo 6 de 2003). South Africa's new investment policy framework and protection for SA firms investing abroad. Tralac-Trade Law Center. Disponible en: http://www. tralac.org/2013/03/06/south-africasnew-investment-policy-frameworkand-protection-for-sa-firms-investingabroad/

- Tratados y Acuerdos

- Acuerdo de Promoción Comercial entre la República de Colombia y Canadá.

- Acuerdo de Promoción y Protección de Inversiones entre el Reino Unido e Irlanda del Norte y Egipto. Londres, 11 de junio de 1975.

- Acuerdo de Libre Comercio entre Chile y Colombia. Acuerdo de Complementación Económica ACE No. 24 suscrito entre Colombiay Chile, el 6 de diciembre de 1993. Derivado del ACE No. 24 en desarrollo a lo establecido en el artículo 20, Capítulo X, Colombia y Chile suscribieron el Acuerdo para la Promoción y Protección Recíproca de las Inversiones, el 20 de enero de 2000.

- Acuerdo entre el Reino de España y la República de Colombia para la promoción y protección recíproca de inversiones.

- Acuerdo sobre promoción y protección recíproca de inversiones entre Perú y Colombia. 
- Acuerdo de Promoción y Protección reciproca de inversiones entre la Confederación Suiza y Colombia.

- Acuerdo Bilateral para la Promoción y Protección de Inversiones entre el Gobierno de la República de Colombia y el Gobierno de la República Popular de China.

- Acuerdo para la Promoción y Protección reciproca de inversiones entre Colombia y la República de la India

- Acuerdo entre Colombia y la República de Corea suscrito el 21 de febrero de 2013.

- Acuerdo para la Promoción y Protección Recíproca de Inversiones suscrito entre el Reino Unido Gran Bretaña e Irlanda del norte y la República de Colombia. APPRI firmado el 17 de Marzo de 2010.

- Acuerdo para la Promoción y Protección Recíproca de inversiones entre Japón y Colombia.

- Acuerdo entre Colombia y la Unión Económica Belgo-Luxemburguesa.

- Acuerdo de Libre Comercio entre la República de Colombia y la República de Costa Rica.

- Acuerdo Comercial entre Colombia, Perú y la Unión Europea

- Acuerdo de Asociación Económica entre Colombia y Japón.

- Convención sobre el Reconocimiento y la Ejecución de las Sentencias Arbitrales Extranjeras o convención de New York de 1958.

- Convenio sobre Arreglo de Diferencias Relativas a Inversiones entre Estados y Nacionales de otros Estados o Convención de Washington de 1965.

- Convención Interamericana sobre Arbitraje Comercial Internacional o Convención de Panamá de 1975.

- Tratado de Libre Comercio de América del Norte entre el gobierno de Canadá, México y Estados Unidos. Diciembre 17, 1992.

- TLC Estados Unidos-Colombia.
- TLC México-Colombia-Venezuela.

- TLC Colombia -

Salvador-Guatemala-Honduras.

- Jurisprudencia

- Corte Constitucional. Sentencia C-750/08.

- Corte Constitucional. Sentencia C-446 de 2009.

- Corte Constitucional. Sentencia C-608/10.

- Corte Constitucional. Sentencia C-169 de 2012.

- Corte Constitucional. Sentencia de Constitucionalidad C-309 de 2007.

- Corte Constitucional. Sentencia de Constitucionalidad C-008 de 1997 y C-961 de 2003.

- Corte Constitucional. Sentencia de Constitucionalidad C-150 de 2009.

- Corte Constitucional. Sentencia T-058 de 2009. Febrero 2 de 2009.

- Corte Constitucional. Sentencia T-225 de marzo 23 de 2010.

- Corte Constitucional. Sentencia C-199 de 2012.

- Corte Constitucional. Sentencia T-288 de 2013. Mayo 20 de 2013.

- Casos CIADI

- Caso CIADI No. ARB/76/1. Gabón contra la Société de Serete S.A.

- Caso CIADI No ARB/07/03. Gobierno de la Provincia de East contra PT Kaltim Prima Coal y otros.

- Caso CIADI No ARB/02/18. Tokios Tokelés c/ Ucrania..

- Caso CIADI No ARB/97/7. Maffezini (Emilio Agustín) c/ España. Decisión de jurisdicción, 25 de enero de 2000.

- Caso CIADI No ARB/02/3. Aguas del Tunari c/ Bolivia. Decisión de objeciones de jurisdicción 2005.

- Caso CIADI No ARB(AF)/00/2. Técnicas Medioambientales Tecmed SA c/ México. Laudo de mayo 29 de 2003.

- Caso CIADI No ARB/01/7. MTD Equity Sdn Bhd y MTD Chile SA c/ República de Chile. Laudo de mayo 25 de 2004. 
- Caso CIADI No ARB/02/8. Siemens AG c/ Argentina. Decisión de Agosto 3 de 2004.

- Caso CIADI No ARB/02/13. Salini Costruttori SpA y Italstrade SpA c/ Jordania. Decisión de noviembre 15 de 2004.

- Caso CIADI No ARB/03/24. Plasma Consortium Ltd c/ República de Bulgaria. Decisión de Febrero 8 de 2005.

- Caso CIADI No ARB/ 07/17. Impregilo S.p.A. c/ Argentina.

- Caso CIADI No. ARB/07/31. Hochtief Aktiengesellschaft c/ Argentina.

- Caso CIADI No ARB/98/2. Víctor Pey Casado y President Allende Foundation c/ Chile.

- Caso CIADI No ARB/03/16. ADC Affiliate Limited y ADC \& ADMC Management Limited c/ República de Hungría.

- Caso CIADI No ARB/05/15. Waguih Elie George Siag y Clorinda Vecchi c/ República Árabe de Egipto.
- Caso CIADI No ARB/04/2. Western NIS Enterprise Fund c/ Ucrania.

- Caso CIADI No ARB/10/25. Border Timbers Limited, Border Timbers International (Private) Limited, y Hangani Development Co. (Private) Limited c/ República de Zimbabue.

- Caso CIADI No ARB/10/15. Bernhard von Pezold y otros c/ República de Zimbabue.

- Caso CIADI No ARB/12/12. Vattenfall y otros c/ Alemania. (Pendiente).

- Caso CIADI No ARB/09/6. Vattenfall AB, Vattenfall Europe AG, Vattenfall Europe Generation AG c/ Alemania. Laudo marzo 11 de 2011.

- Centro Internacional de Arreglo de Diferencias Relativas a Inversiones -CIADI-. Carga de Casos del CIADI-Estadísticas. Edición 2013-1. 
